\title{
SUBSTITUTED BEDT-TTF DERIVATIVES: SYNTHESIS, CHIRALITY, PROPERTIES AND POTENTIAL APPLICATIONS.
}

\author{
John D. Wallis* and Jon-Paul Griffiths \\ School of Science, The Nottingham Trent University, Clifton Lane, \\ Nottingham NG11 8NS, U.K., email: john.wallis@ntu.ac.uk
}

\begin{abstract}
.
The increasing availability of functionalized BEDT-TTF derivatives in both racemic and enantiopure forms opens up great opportunities for preparing multifunctional materials and chiral conducting systems in the form of crystals, thin films and polymers. Functionalities such as amino and carboxyl will allow attachment to other molecular systems, while intermolecular interactions between substituents, e.g. hydrogen bonding and halegon- - - halegon interactions, provides additional tools for designing solid state radical cation structures. In this review the syntheses of substituted derivatives of BEDTTTF and closely related donors are surveyed, along with the structures and properties of the radical cation salts so far prepared, as a stimulus for future application of these versatile and attractive molecules. Particular attention is paid to the preparation of single enantiomers, and to the stereochemical consequences of the synthetic procedures.
\end{abstract}

\section{Introduction}

Organosulfur donor molecules have been a major focus for research in the preparation of molecular conducting systems, with tetrathiafulvalene $\mathbf{1}$ and its derivatives playing a leading role initially. ${ }^{1}$ However, breakthroughs in the last decade for preparing superconducting and hybrid materials have featured bis(ethylenedithio)tetrathiafulvalene 2, also known as BEDT-TTF or ET. ${ }^{2}$ This molecule shows two reversible oxidations at 0.50 and $0.91 \mathrm{~V}$ relative to the $\mathrm{Ag} / \mathrm{AgCl}$ electrode, $c a .0 .15 \mathrm{~V}$ more positive than those for TTF, and has been converted into a very large number of radical cation salts. These have been studied by a wide range of techniques stimulated in part by formation of superconducting radical cation salts with anions $\mathrm{Cu}(\mathrm{NCS})_{2}{ }^{-}, \mathrm{Cu}\left(\mathrm{N}(\mathrm{CN})_{2}\right) \mathrm{X}^{-}(\mathrm{X}=\mathrm{Br}, \mathrm{Cl})$ and $\mathrm{ICl}_{2}{ }^{-}$with $\mathrm{T}_{\mathrm{c}}$ 's in the range 10-14.2 $\mathrm{K}^{3}$. Studies have concentrated on the electrical and magnetic properties but include the role of intermolecular S---S attractions, lattice vibrations and disorder in determining these properties, polymorph formation and phase transitions. The greatest interest is in the low temperature solid state physics, especially 
of the superconducting systems, since the salts are clean systems whose electrical structures can be modeled. Further highlights include a paramagnetic superconducting radical cation salt with $\left[\mathrm{Fe}(\text { oxalate })_{3}\right]^{3-4}$, and a layered salt with a mixed chromium(III) / manganese (II) oxalate network which has independent electrical and ferromagnetic properties. $^{5}$ The main variations to the ET structure have been to interchange some sulfur atoms for another Group VIB element, ${ }^{6}$ or to vary the positions of the S atoms. ${ }^{7}$ Thus, replacement of the inner set of sulfur atoms in ET by seleniums gives BETS 3 in which, remarkably, the superconducting properties of particular polymorphs of (BETS) ${ }_{2} \mathrm{FeX}_{4}{ }^{-}$ $(\mathrm{X}=\mathrm{Cl}, \mathrm{Br})$ can be turned on or off by an external magnetic field. ${ }^{8}$ Attachment of substituents to ET bring potential for linking to greater molecular frameworks, for incorporating hydrogen bonding functionality to promote ordering of the radical cation salts, and for introducing chirality. The latter is of particular interest following Rikken's observation of magnetochiral anisotropy in carbon nanotubes. ${ }^{9}$ Here we review the progress in the preparation of functionalised derivatives of ET with the aim of stimulating studies on the properties of these very interesting systems. Special attention has been paid to the preparation of chiral systems, and issues of stereochemistry. No syntheses have been reported on substituted analogues of ET donors in which some or all ring sulfur atoms are replaced by selenium, though this may change soon following recent important advances in the syntheses of the unsubstituted systems and their precursors. ${ }^{10}$

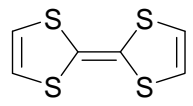

1

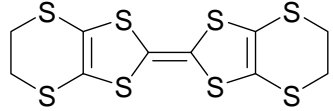

2

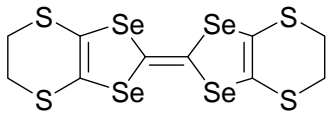

3

\section{Synthetic strategies.}

TTF can be readily functionalised by lithiation and subsequent reaction with electrophiles, but the synthesis of ET derivatives must follow a different route, since lithiation is likely to lead to break up of the outer rings as has been observed in other basic conditions. ${ }^{11}$ Thus, the synthetic strategy to a mono-substituted ET 10 involves construction of the central double bond late in the synthesis by reaction of a suitably substituted oxo compound 8 with excess of the unsubstituted thione 9 in triethyl phosphite (Scheme 1). Unsubstituted ETs and a group of disubstituted derivatives 11-12 are formed by homo-coupling reactions, but usually can be separated from the desired cross coupled material by flash chromatography. Coupling of two oxo compounds gives generally lower yields of cross coupling products, since the thione is the preferred substrate for ylid formation with triethyl phosphite, and the ylid reacts preferentially with the polar carbonyl group of the oxo compound. ${ }^{12}$ Dicobalt octacarbonyl couplings of thiones ${ }^{13}$ has not been used successfully to date in the synthesis of substituted ET's. The oxo compound is prepared from the corresponding thione (e.g. 8 from 6) using the well established treatment with mercuric acetate in chloroform with additional acetic acid, though inclusion of acetic acid may not be an absolute requirement. There are two main strategies for the formation of the substituted thione. The first is by two nucleophilic displacements by the dithiolate 5 , usually as its sodium salt, on a vic-dihalide ${ }^{14}$ or on a cyclic sulfate ester. ${ }^{15}$ The latter is used when an enantiopure thione is required, and the cyclic sulfate ester is prepared from the corresponding vic-diol. These two routes were used in the syntheses of methyl ET-ethanoate $\mathbf{1 3}$ in racemic ${ }^{16}$ and enantiopure forms 
respectively. ${ }^{17}$ The second procedure, introduced by Neilands, ${ }^{18}$ uses a hetero Diels Alder reaction of the trithione 7 with a mono-substituted alkene to provide the racemic thione. The disodium salt of dithiolate $5^{19}$ and the trithione $7^{18,19}$ can be readily prepared from 4, a zinc(II) complex of the dithiolate, which is readily prepared from carbon disulfide and sodium ${ }^{20}$ all reactions being feasible on a large scale. The less reactive zinc complex 4 will also undergo reaction with some vic-dibromides to give the bicyclic thiones e.g. with 1,2-dibromoethane and 2,3-dibromo-1-methoxypropane. ${ }^{14}$ The synthetic procedures are easily adapted to preparation of disubstituted ETs where those substituents are cis or trans to each other on the same outer ring by choice of appropriate material for reaction with $\mathbf{5}$ or $\mathbf{7}$.
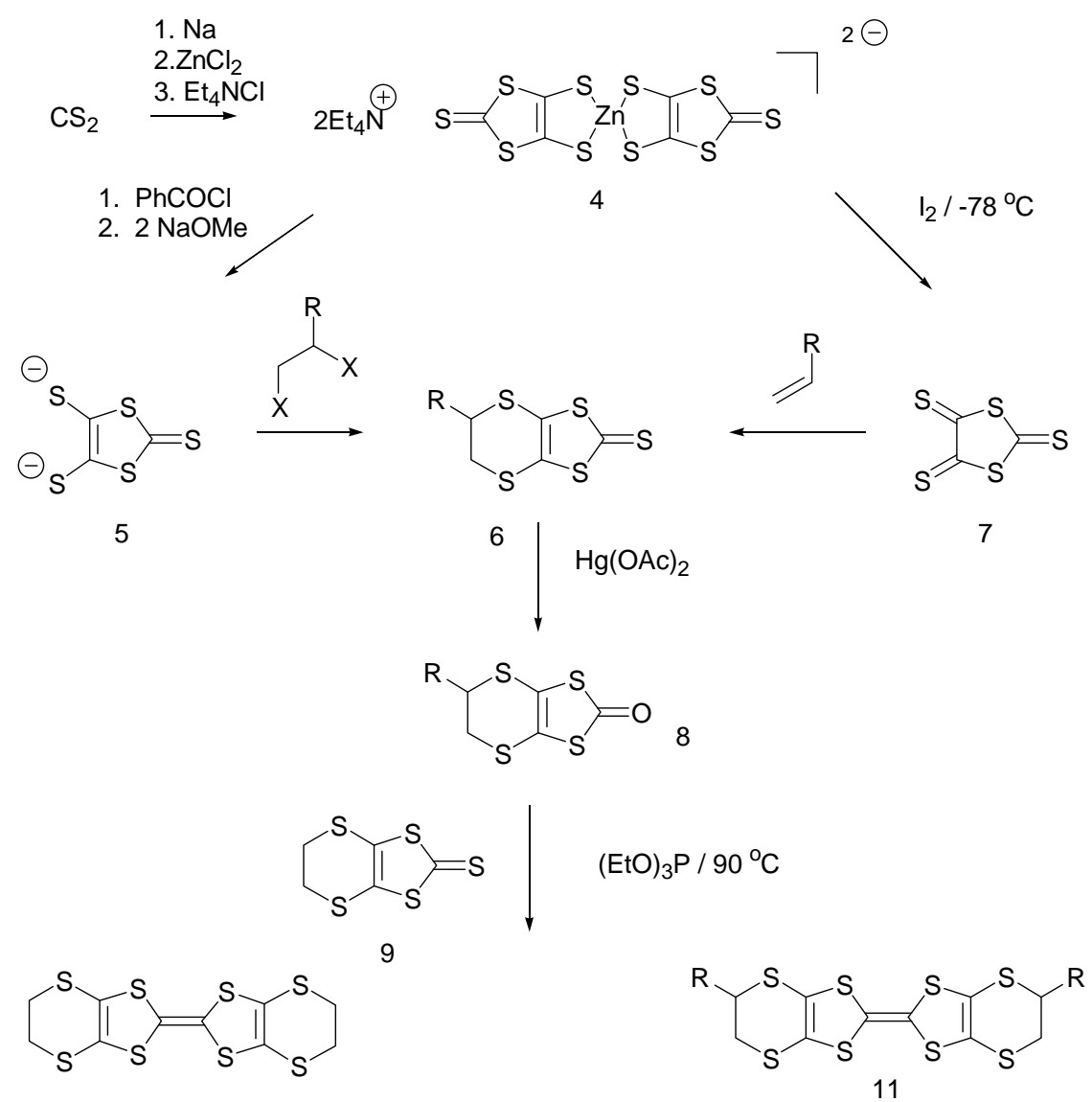

2

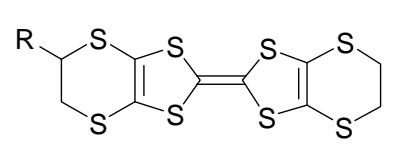

10

Scheme 1

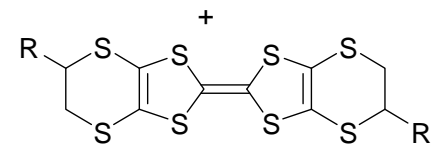

12

If chromatographic separation of cross coupled and homo coupled donors is very difficult, for example when the substituents on the two components for coupling are 
similar, an alternative, much less explored, strategy is to build one of the ethylene bridges at the end of the synthesis. Thus, Zambounis and Mayer prepared the SEM protected dithiolate 14 by cross coupling, removed the protecting groups and reacted the resulting dithiolate 15 with 1,2-dibromoethane to give $S, S$-dimethyl-ET, DIMET 16. ${ }^{11}$ Cyanoethyl protection ${ }^{21}$ of the dithiolate has been utilized too. ${ }^{22}$ This approach may be applicable to preparation of ET derivatives containing functionality which is sensitive to the triethyl phosphite coupling reaction by installation of the substituted ethylene bridge at the end of the synthesis. Becher's bis(cyanoethyl) protected donor $\mathbf{1 7}$ provides ready access to the unsubstituted dithiolate $18 .^{21}$ Specific methods for preparing analogues of VT, the fully unsaturated version of ET, 19, will be referred to later.

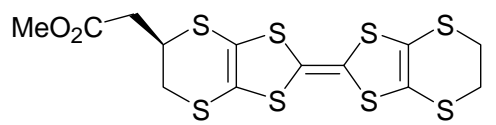

13

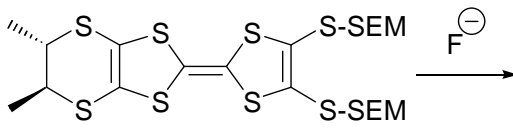

14

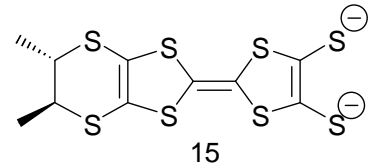

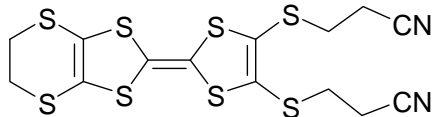

17

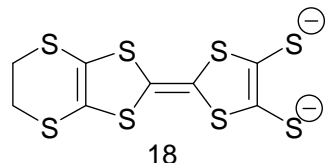

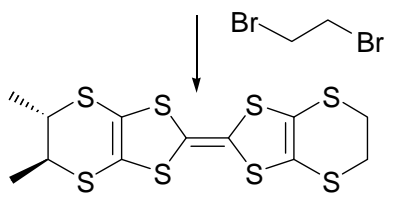

16

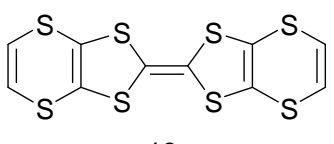

19

\section{Stereochemical considerations.}

Preparation of single isomers of ET derivatives with substituents at both ends of the molecule, requires some careful consideration of the stereochemical results of the coupling reaction (Scheme 2). Thus, self coupling of the enantiopure monosubstituted oxo compound 20, gives two chiral diastereomers 21 and 22, which are likely to be very difficult to separate. If the oxo compound is racemic then the number of stereoisomers jumps to six: two pairs of enantiomers, 21-24, and two further diastereomers - 25 with a mirror plane, and 26 with a centre of symmetry, with little likelihood of separation! In contrast, self coupling of enantiopure trans symmetrically disubstituted materials such as 27 will give just one enantiopure tetrasubstituted ET derivative 28, as achieved for tetramethyl-ET, TMET. ${ }^{15}$ The racemate of $\mathbf{2 8}$ is best prepared by mixing equal amounts 
of the two enantiomers 28 and 29, since cross coupling of racemic 27 will give also give a meso compound $\mathbf{3 0}$ along with $\mathbf{2 8}$ and 29. Self coupling of the cis disubstituted oxo compound 31 will give two diastereoisomers 32 and 33.
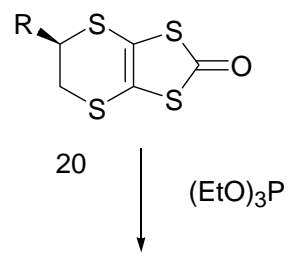

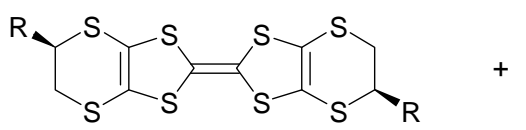

21

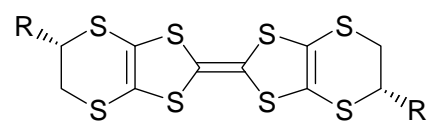

23

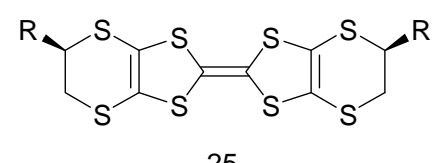

25
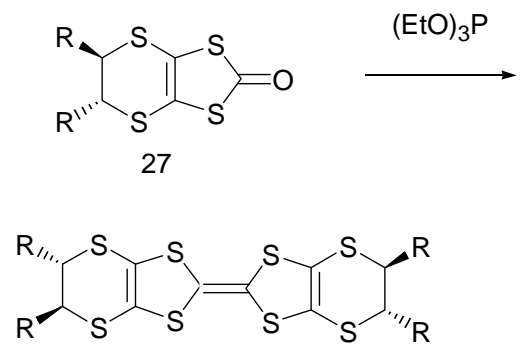

29

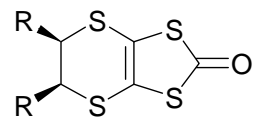

31
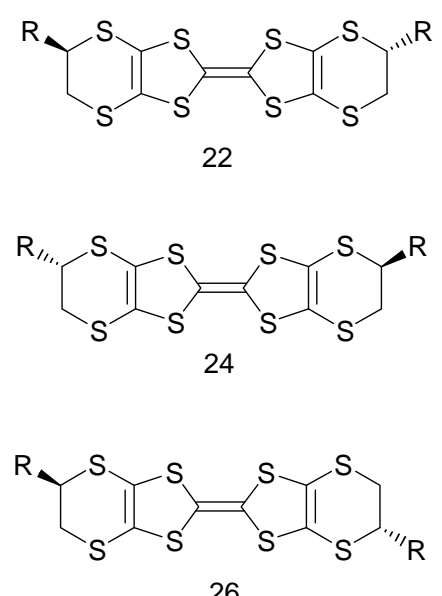

26
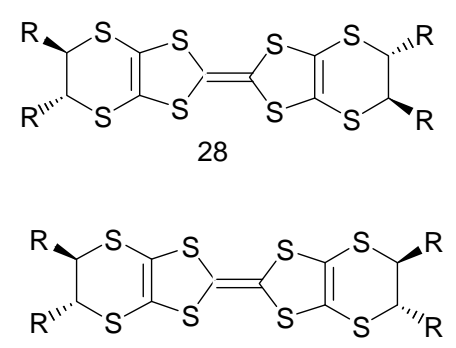

30
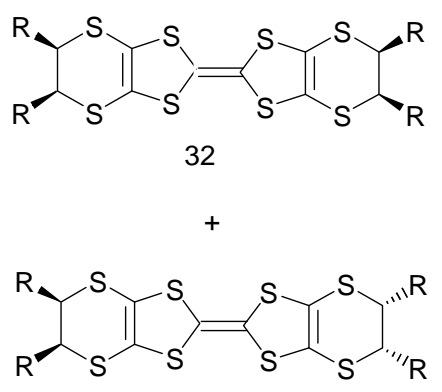

33

Scheme 2 
Cross coupling of two different substituted components to give a single diastereoisomeric product needs careful thought too. Favourable situations are if one component has $\mathrm{C}_{2}$ symmetry then one cross coupled diastereosiomer is produced if both components are enantiopure, e.g. preparation of trisubstituted and tetrasubstituted derivatives 34 and 35 (Scheme 3), or if one component is achiral, e.g. preparation of the enantiopure tris(hydroxymethyl) donor $39,{ }^{23}$ in which a chiral monosubstituted oxo compound 36 is cross coupled to the achiral disubstituted oxo compound $\mathbf{3 7}$ to give a single diastereoisomer 38 (Scheme 4).

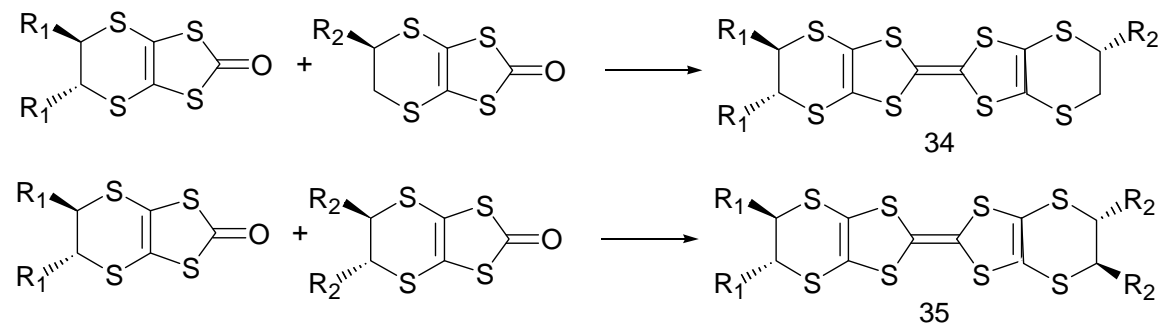

Scheme 3

Cross coupling of a cis disubstituted thione and a trans disubstituted oxo compound will give one product, enantiopure or racemic depending on the trans component. Wallis utilized this in the synthesis of the racemic cis, trans tetrakis(hydroxymethyl)ET 43 (Scheme 5). ${ }^{24}$ To ensure separation of the cross coupled product from homocoupled products, the two diol components were protected with groups of quite different polarities, in this case t-butyldiphenylsilyl and acetyl groups. Coupling of the protected compounds $\mathbf{4 0}$ and $\mathbf{4 1}$ in triethyl phosphite led to cross coupled product 42 (two protecting groups of each type) which had different chromatographic properties from homocoupled products (with four identical protecting groups). Subsequent hydrolysis of $\mathbf{4 2}$ yields the tetrol $\mathbf{4 3 .}$

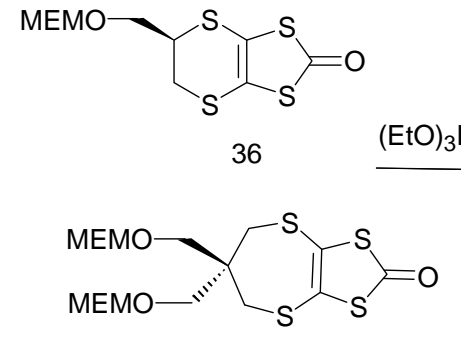

37

$\mathrm{MEM}=\mathrm{CH}_{2} \mathrm{OCH}_{2} \mathrm{CH}_{2} \mathrm{OMe}$

Scheme 4
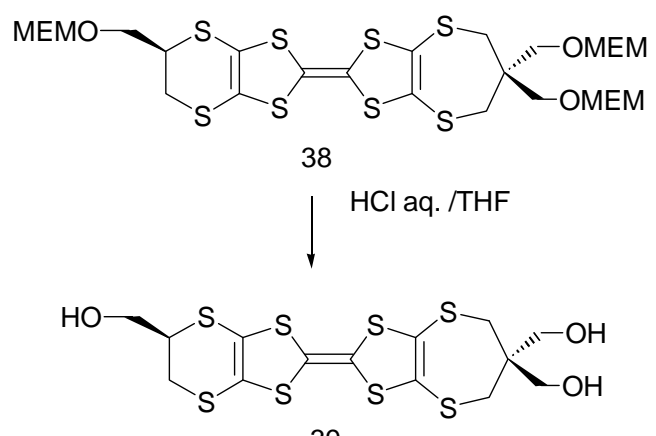

39 


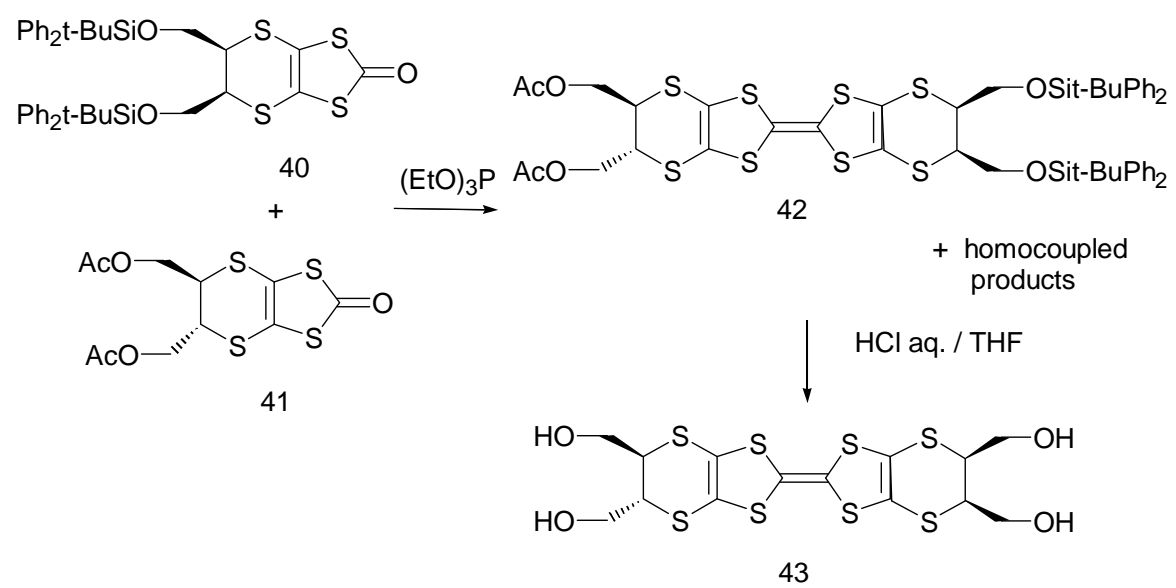

Scheme 5

\section{Substituted ETs.}

We now survey the range of known ET derivatives and closely related donors most of which have been reported in the last ten years. Studies of their radical cation salts are still at an early stage, but results will be indicated when available. Most structural data refers to salts of ETs carrying two or four ethyl, methyl or halo groups, though two salts of bis(hydroxymethyl)functionalized donors have been characterized. Thus, it is too early to identify many general principles regarding the influence of substituents on crystal packing arrangements of the radical cation salts. Apart from production of new conducting solids, these functionalised ETs may find applications as mediators in electrochemical processes, e.g. in biosensors, in catalytic processes, and in conducting polymers and thin films. Compared to ET, the substituted donors are often much more soluble in organic solvents.

\section{Alkyl Substituted ETs.}

Surprisingly, only three racemic monoalkyl-ET derivatives have been reported, the methyl derivative $\mathbf{4 4}$ was prepared by the Zambounis and Mayer method installing the ethylene bridge last, ${ }^{11}$ and the hexadecyl and octadecyl derivatives $\mathbf{4 5}$ and $\mathbf{4 6}$ by cross coupling methodology after hetero Diels Alder reaction of the trithione 7 with octadec-1ene or eicosene. ${ }^{25,26}$ Brief reference has been made to preparing $\mathbf{4 4}$ from ester-substituted donors by treatment with lithium bromide in HMPA at $150^{\circ} \mathrm{C} .{ }^{27}$ No radical cation salts of either derivative have been reported, even though the former represents one of the smallest perturbations to the structure of ET. However, the methylated oxo compound 47, prepared from dithiolate 5 and 1,2-dibromopropane followed by $\mathrm{S} / \mathrm{O}$ exchange using mercuric acetate, has been self coupled to give a mixture of dimethyl-ETs 48, which has been converted to radical cation salts formulated as $(48) \mathrm{I}_{5},(48)_{8 / 3} \mathrm{CuCl}_{2}$ and $(48) \mathrm{HgCl}_{3}$, the latter of which shows a transition to a metallic state on cooling below $50 \mathrm{~K} .{ }^{28}$ It is not known which of the six stereoisomers of $\mathbf{4 8}$ are involved in each case. Dunitz prepared the enantiopure tetramethyl-ET, S,S,S,S-TMET, 52, the first reported chiral organosulfur donor, in 1986 by self coupling of the trans-dimethyl thione $51 .^{15}$ The latter is formed in $30 \%$ yield by reaction of dithiolate 5 with the enantiopure cyclic sulfate ester $\mathbf{5 0}$ which is prepared in two steps from the corresponding $R, R$-butane-2,3-diol via cyclic sulfite ester 49 (Scheme 6). Dunitz and Hilti reported two series of radical cation salts: a 
semiconducting 2:1 series with $\mathrm{PF}_{6}^{-}, \mathrm{AsF}_{6}^{-}, \mathrm{SbF}_{6}^{-}$(and a structurally related incommensurate salt with $\mathrm{I}_{3}^{-}$) and a series with approximate $3: 2$ stoichiometry with $\mathrm{ClO}_{4}^{-}$, $\mathrm{ReO}_{4}{ }^{-}, \mathrm{BF}_{4}{ }^{-}$showing metallic behaviour in the plane of the layers of donor molecules. ${ }^{29}$ For the perchlorate and tetrafluoroborate 3:2 salts, anions lie in large channels surrounded by methyl groups, and are positionally disordered (Fig. 1). Detailed studies on the perchlorate salt showed the anions are accompanied by solvent molecules the composition of which has a marked influence on the electrical properties. Outer rings of TMET adopt envelope conformations with the methyl groups in pseudoequatorial positions. Care is needed in the refinements of the crystal structures since the packing arrangements are pseudocentrosymmetric, often only the positions of the methyl groups break the symmetry. ${ }^{29,30}$ A reported crystal structure on the "racemic" donor TMET (prepared from racemic 51) almost certainly contains a disordered mixture of racemic 52 and the meso isomer 53. ${ }^{31}$ Keller electrocrystallised an unspecified mixture of TMET isomers: a metallic 2:1 salt with $\mathrm{PF}_{6}^{-}$appears to contain the isomer 54, and a chlorobenzene solvate of a 1:1 $\mathrm{PF}_{6}{ }^{-}$salt appears to contains both isomers 54 and 55 in a pseudosymmetrical arrangement. ${ }^{32}$ In both cases the relation between adjacent methyl groups is cis and one methyl group will lie in an axial position for an envelope conformation of the outer ring. Great care is necessary in interpreting crystallographic results on materials grown from an isomeric mixture of donors; it is far preferable to work with one single isomer, and this eliminates one source of disorder in the salts as well.

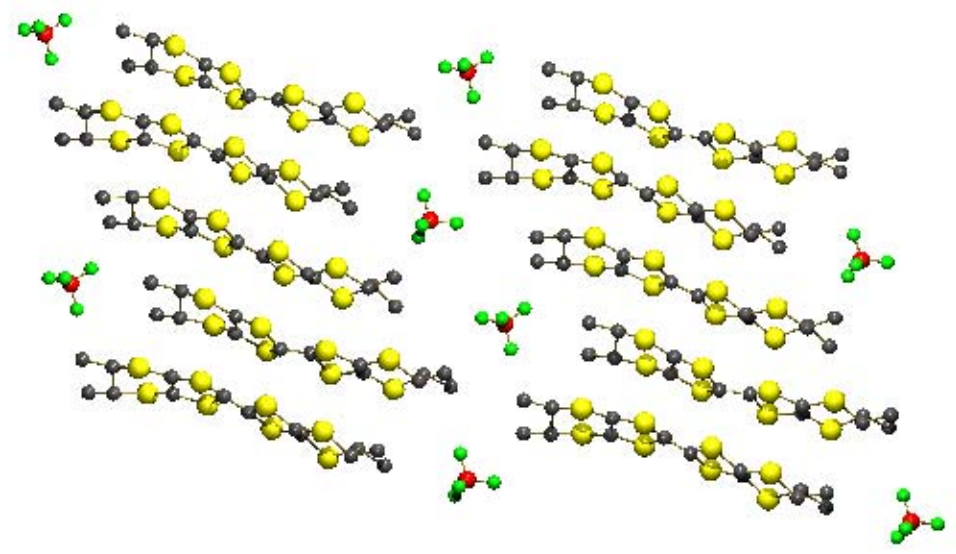

Figure 1. Crystal packing in $(\mathrm{TMET})_{3}\left(\mathrm{BF}_{4}\right)_{2}$ showing one set of positions of the disordered anions in the wide channel formed by the donors'methyl groups. 

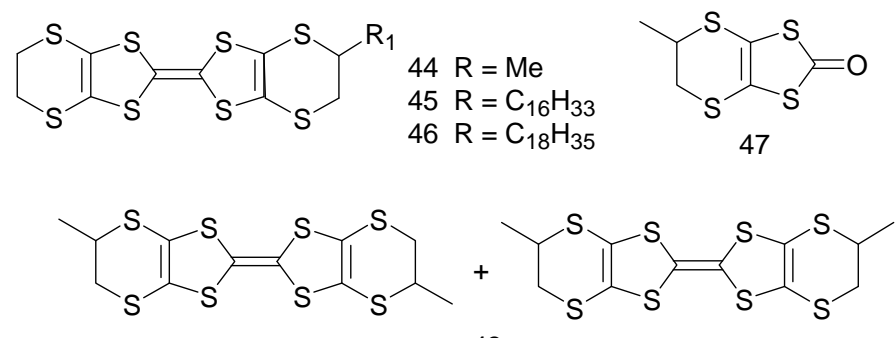

48

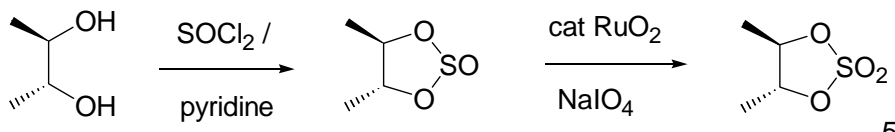

$49-50$

$\underbrace{49}_{S} \|_{S}^{S}=S$

52

51

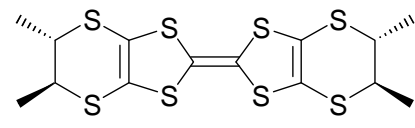

53

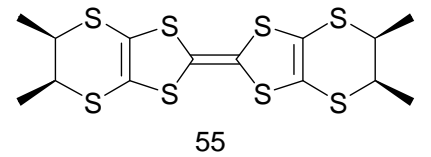

Scheme 6

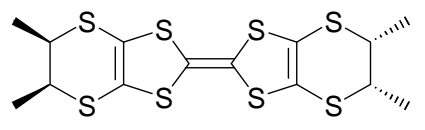

54

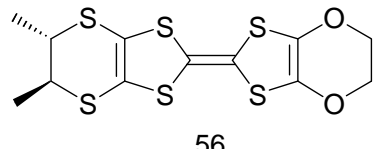

56

Zambounis and Hilti prepared the enantiopure dimethyl-ET, S,S-DIMET, 16, and its $\kappa$-phase 2:1 $\mathrm{ClO}_{4}^{-}$salt which, under pressure, became superconducting at $2 \mathrm{~K}^{33}$ as well as salts with symmetrical linear anions, $\mathrm{AuI}_{2}{ }^{-}, \mathrm{Au}(\mathrm{CN})_{2}^{-}, \mathrm{AuBr}_{2}{ }^{-}, \mathrm{I}_{3}^{-}{ }^{-34}$ Sugawara and Kawada reported a series of semiconducting 2:1 radical salts of enantiopure DIMET with $\mathrm{PF}_{6}^{-}, \mathrm{ClO}_{4}^{-}$and $\mathrm{ReO}_{4}{ }^{-}$, as well as the racemic version of the $\mathrm{PF}_{6}{ }^{-}$salt. ${ }^{35}$ The $\mathrm{PF}_{6}{ }^{-}$case provides the only structurally comparable pair of radical cation salts of enantiopure and racemic donors. Interestingly, the centrosymmetric anion is only ordered in the latter case where the hole in which it lies is not chiral. Both enantiopure and racemic salts showed head to tail stacking of donors with the main axes of neighbours twisted at $c a .30^{\circ}$ to each other (Fig. 2). Keller reports a range of salts with DIMET including an enantiopure semiconducting 1:1 $\mathrm{BF}_{4}$ salt. $^{32}$ Although methyl groups take pseudoequatorial positions in the structurally characterised radical cation salts, for neutral DIMET the methyl groups take pseudo-axial positions. ${ }^{31}$ The enantiopure dimethylated donor $\mathbf{5 6}$ in which two $\mathrm{O}$ atoms have replaced the $\mathrm{S}$ atoms in one outer ring has been prepared by cross coupling. ${ }^{12}$ 


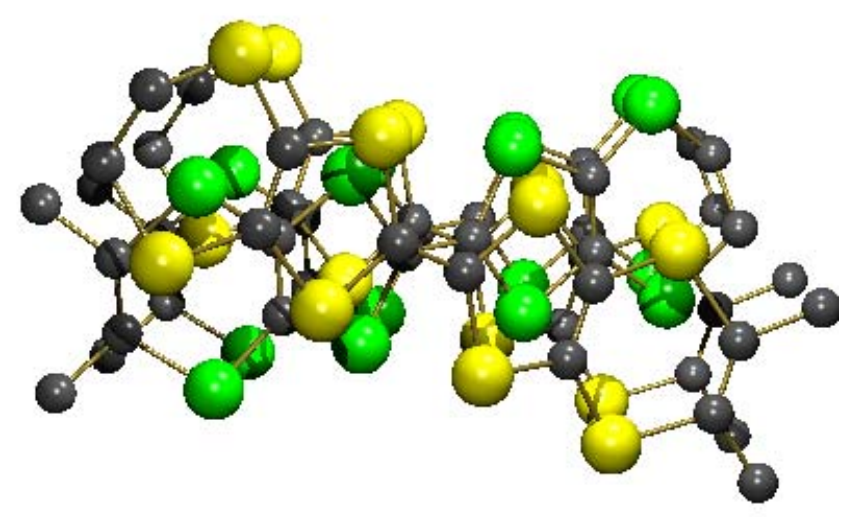

Figure 2. View down a stack of donor molecules in racemic (DIMET) ${ }_{2} \mathrm{PF}_{6}$ showing the twisting of one donor relative to its neighbours.

Kini has prepared the racemic trans-diethyl-thione 57 by reaction of the trithione 7 with trans-hex-3-ene. Conversion to the corresponding oxo compound followed by heating with triethyl phosphite gave the homocoupled derivative, TEET, as a mixture of a racemate 58 and the meso compound 59 (Scheme 7). ${ }^{36}$ The corresponding tetra-n-propyl derivative was made from trans-oct-4-ene. Electrocrystallisations of the diastereoisomeric mixture of TEET did not give any 2:1 salts, but insulating salts of dications (with $\mathrm{AuCl}_{2}{ }^{-} / \mathrm{AuCl}_{4}{ }^{-}$or $\mathrm{Br}-\mathrm{I}-\mathrm{Br}{ }^{-}$) or monocations (with $\mathrm{I}_{3}{ }^{-}$or $\mathrm{ClO}_{4}{ }^{-}$). X-ray studies show that either the racemate (with $\mathrm{I}_{3}{ }^{-}$), the meso compound (with $\mathrm{IBr}_{2}{ }^{-}$) or a disordered mixture of both (with $\mathrm{AuCl}_{2} / \mathrm{AuCl}_{4}$ ) are present in these crystals. In all cases, including the neutral donor, the ethyl groups take axial orientations. The linear anions are closely associated with the sulfur systems of donors, thus disrupting the expected close packing of donor molecules. The racemic diethyl-ET $\mathbf{6 0}$ was prepared by cross coupling, and forms a semiconducting 2:3 salt with $\mathrm{Br}-\mathrm{I}-\mathrm{Br}$ ", with anions lying parallel to donors in a 1:1 ratio in layers which are interleaved by "anion only" layers.

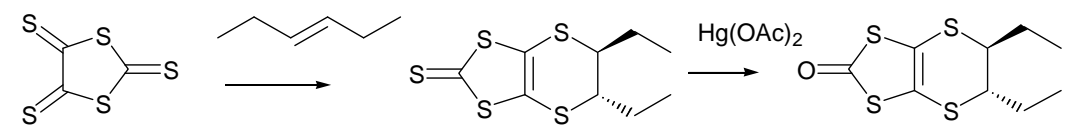

57<smiles>CCC1SC2=C(SC(=C3SC4=C(S3)C3CCCCC3S4)S2)SC1CC</smiles><smiles>CCOCCCOCC</smiles><smiles>CCC1SC2=C(SC(=C3SC4=C(S3)S[C@H](CC)C(CC)S4)S2)SC1CC</smiles><smiles>CCC1SC2=C(SC(=C3SC4=C(SCCS4)S3)S2)SC1CC</smiles> 
Several thiones containing an extra fused ring have been reported, e.g. 61-66. The first two were prepared by cycloaddition of cyclopentene or cyclohexene with trithione $7,{ }^{37}$ while unsaturated analogues were prepared by reaction of an $\alpha$-chlorocycloalkanone with the dithiolate 5 to give mixtures of two isomers, e.g. 63 and $64 .^{38}$ Conversions to homocoupled ET derivatives are reported, though those from 61-63 and 65 are likely to be a mixture of two diastereoisomers, e.g. 67 and $\mathbf{6 8}$ from 61. Salts of some donors have been reported including an X-ray structure of a 1:1 triiodide salt of 67 in which the linear anions surround pairs of donors (Fig. 3). ${ }^{39}$ Donor 69 with two fused cyclododecane rings was reported by Abashev, and forms a 1:1 complex with $\mathrm{C}_{60}$ though there is no structural data to determine which isomer is involved. ${ }^{40}$ Donors fused to one cyclopentyl or cyclohexyl ring were prepared by cross coupling with a bis-S-cyanoethyl protected component, deprotection and cyclisation with 1,2-dibromoethane. ${ }^{21}$ Cyclisation of trithione 7 with indene has been reported. ${ }^{41}$

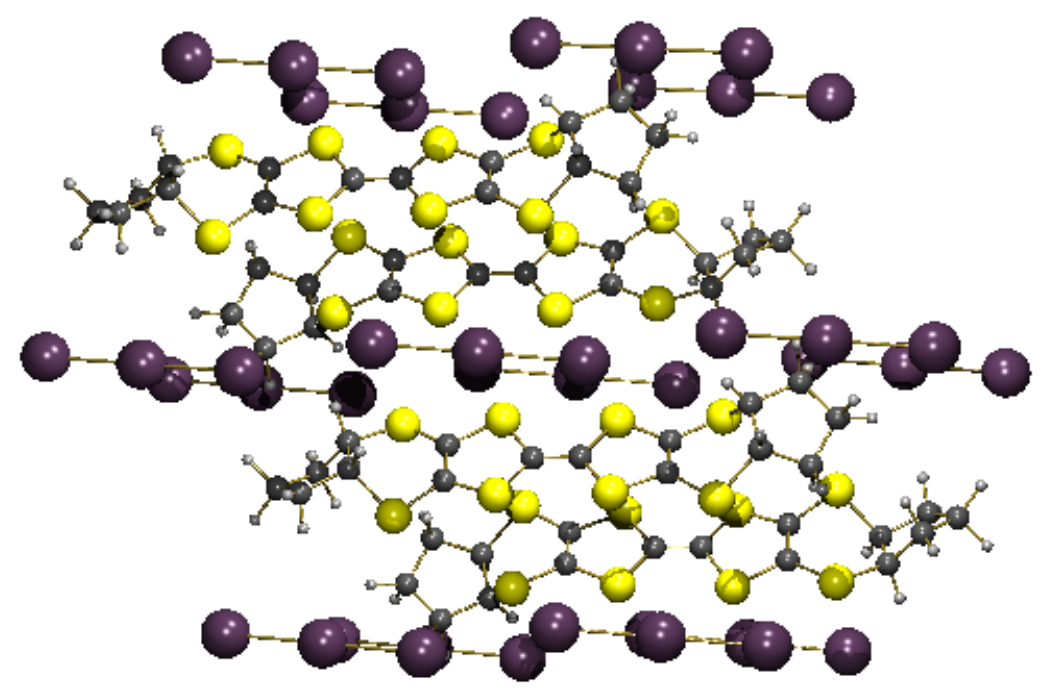

Figure 3. Crystal packing in syn-bis(cyclopentyl)ET triiodide, $(\mathbf{6 7}) \mathrm{I}_{3}{ }^{39}$ 


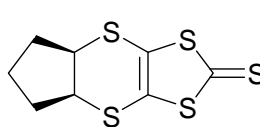

61

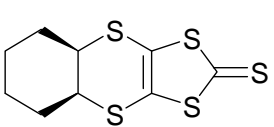

62

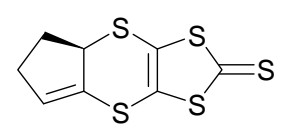

63

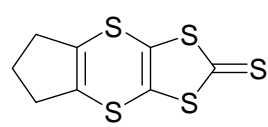

64

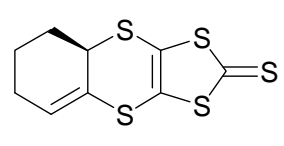

65

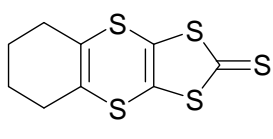

66

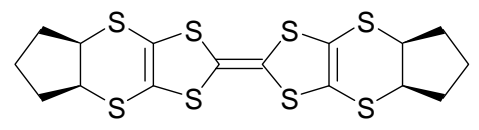

67

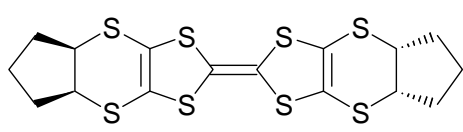

68

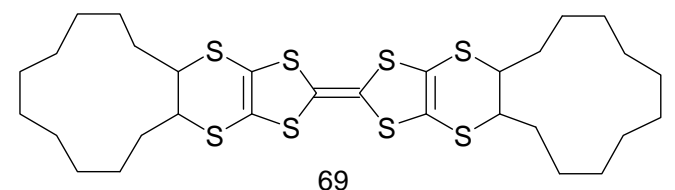

69

\section{Aryl substituted and fused ET derivatives}

The mono- and diphenyl-thiones $\mathbf{7 0}$ and $\mathbf{7 1}$ have been synthesized both by disubstitution of a vic-dibromide with the sodium salt ${ }^{42}$ and zinc complex ${ }^{43}$ of dithiolate 5 and by cycloaddition of styrene or $E$-stilbene with trithione $7 .^{44,45}$ The enantiopure version of $\mathbf{7 1}$ has not been prepared, despite apparent indications in the literature. Attempts to convert $\mathbf{7 1}$ or its oxo compound into ET derivatives have been unsuccessful, homocoupling in triethyl phosphite gave only tetra(ethylthio)TTF 72, the product of Arbusov rearrangements. In contrast, monosubstituted thione $\mathbf{7 0}$ could be homocoupled to give a mixture of diphenyl-ET donors by treatment with triethyl phosphite for 30 minutes at $100-130^{\circ} \mathrm{C} .^{42}$ An alternative two step synthesis of aryl substituted thiones involves formation of the ethoxy thione $\mathbf{7 3}$ from the zinc complex $\mathbf{4}$, and treatment of its solution in a moderately electron rich substituted benzene with tosic acid. ${ }^{46}$ The carbocation $\mathbf{7 4}$ reacts with the aromatic solvent, so that $\mathbf{7 5}$ and $\mathbf{7 6}$ were prepared from toluene and para-xylene respectively (Scheme 8), and even the phenyl derivative 70 could be attained if excess tosic acid was used. This approach has considerable unexplored potential.

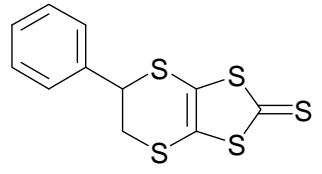

70

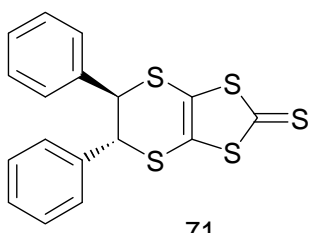

71

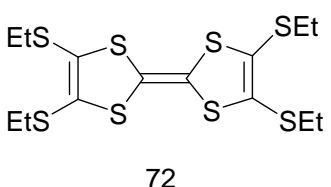

72 


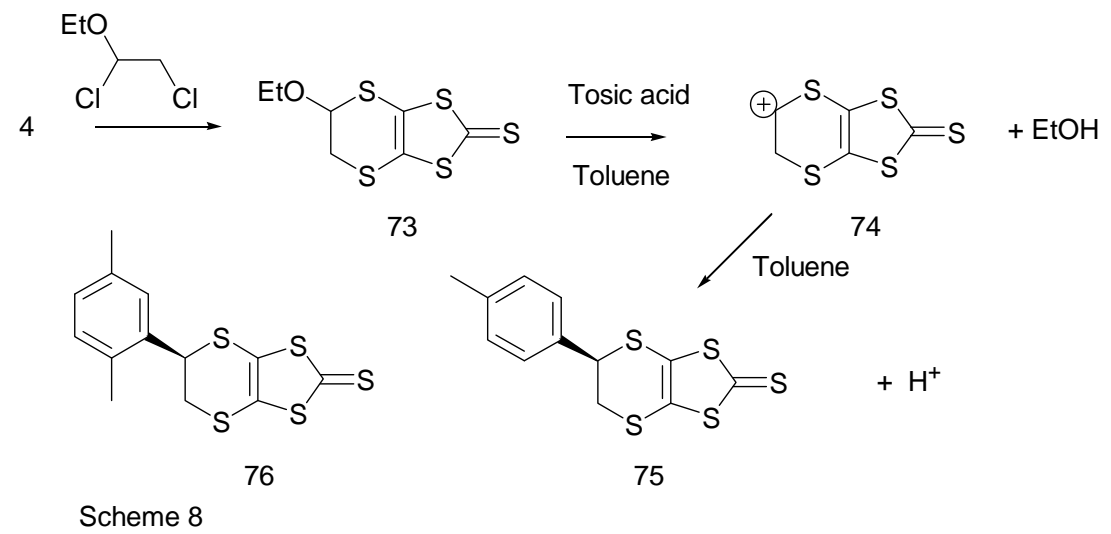

Xu prepared 2- and 4-pyridyl substituted thiones 77-78 from the corresponding vinylpyridines and trithione 7 in $20-25 \%$ yield, ${ }^{47}$ though this has been improved, ${ }^{48}$ and converted them to their oxo compounds which were cross coupled with unsubstituted thione 9 in triisopropyl phosphite to give the monosubstituted donors 79-80. ${ }^{47}$ Donor $\mathbf{7 9}$ forms a 1.1:1 charge transfer complex with TCNQ, and $\mathbf{8 0}$ forms a 1:1 complex with copper(II) chloride both of which have low conductivities $\left(c a .10^{-3} \mathrm{~S} \mathrm{~cm}^{-1}\right)$. Donors 79 and 80 could be dehydrogenated at the substituted bridge with DDQ to give donors 81$82 .{ }^{47}$

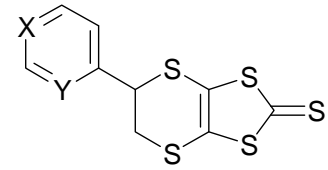

$77 X=\mathrm{CH}, \mathrm{Y}=\mathrm{N}$

$78 X=N, \quad Y=C H$

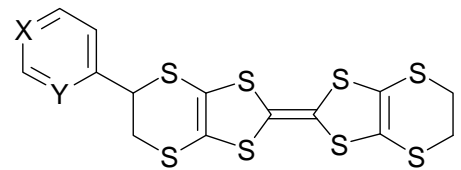

$79 \mathrm{X}=\mathrm{CH}, \mathrm{Y}=\mathrm{N}$

$80 \mathrm{X}=\mathrm{N}, \quad \mathrm{Y}=\mathrm{CH}$

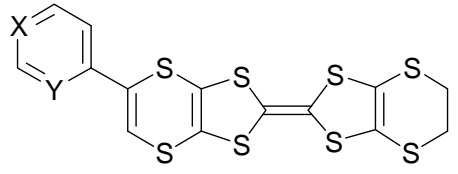

$81 \mathrm{X}=\mathrm{CH}, \mathrm{Y}=\mathrm{N}$

$82 \mathrm{X}=\mathrm{N}, \quad \mathrm{Y}=\mathrm{CH}$

A number of ETs fused to aromatic systems are known. The dibenzo fused ET 83 has been prepared in three ways: (a) Müller started from 1,2-dimercaptobenzene and chloroacetyl chloride, adapting a six step route used to prepare ET (Scheme 9a), ${ }^{49}$ (b) Kini reacted 1,3-cyclohexadiene with trithione 7, followed by dehydrogenation with DDQ to form the benzene ring in thione $\mathbf{8 4}$ and homocoupling in a four step preparation (Scheme $9 b),{ }^{50}$ (c) Elsenbaumer reacted tetralithio-TTF with two equivalents of the $o-$ benzene-bis(disulfide) 85 to give the target in just one step from TTF in $72 \%$ yield (Scheme 9c). ${ }^{51}$ Müller has reported electrocrystallisation gave radical cations, e.g. a 3:1 salt with $\mathrm{AsF}_{6}{ }^{-}$as flexible fine fibres (typical dimensions: 10000 × 50 × $20 \mu \mathrm{m}^{3}$ ) with conductivity of $100 \mathrm{~S} \mathrm{~cm}^{-1}$ along the fibre's axis. ${ }^{49}$ Preparation of a di-hydroxyl and tetrahydroxy-substituted dibenzo-ET has been described. ${ }^{52}$ Kini prepared the naphthalene fused donor 89, by ring closure of endoxide 86 with trithione 7 to give thione 87 followed by ring opening of the strained ether and elimination using polyphosphoric acid to give the thione $\mathbf{8 8}$, which was converted to donor $\mathbf{8 9}$ in two standard steps (Scheme 10). ${ }^{50}$ 
(a)

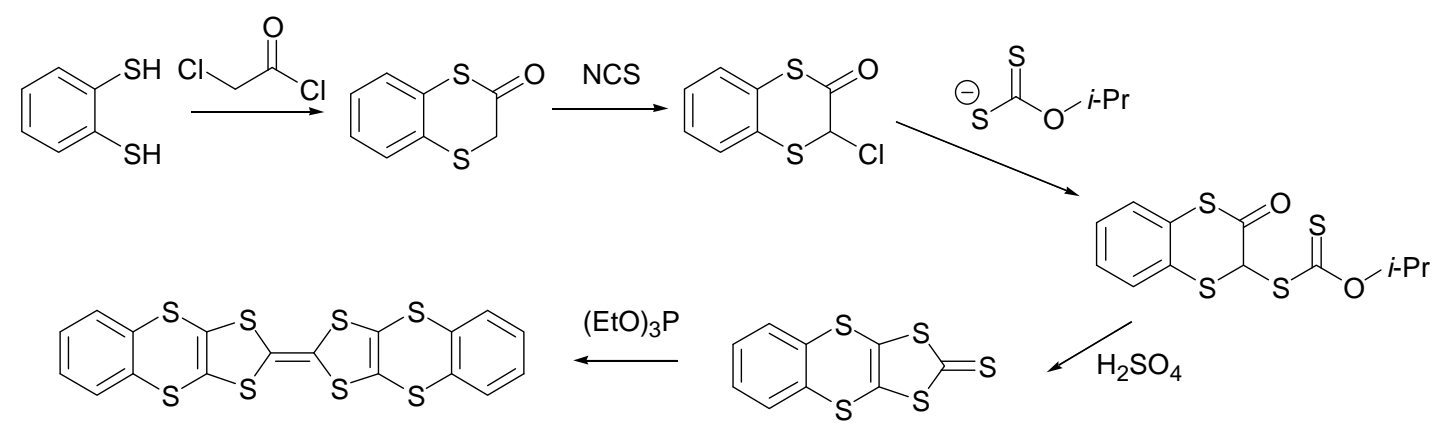

83

(b)

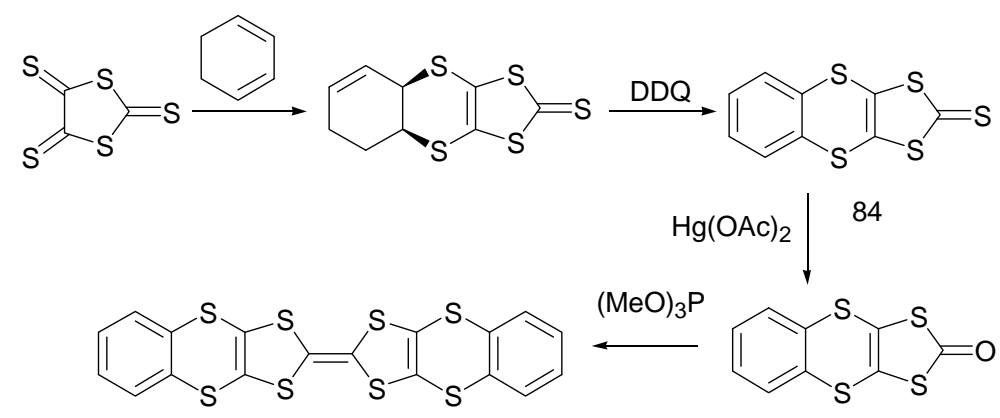

83

(c)<smiles>CCOC(=O)SSSc1ccccc1SSC(=O)OCC</smiles>

Scheme 9

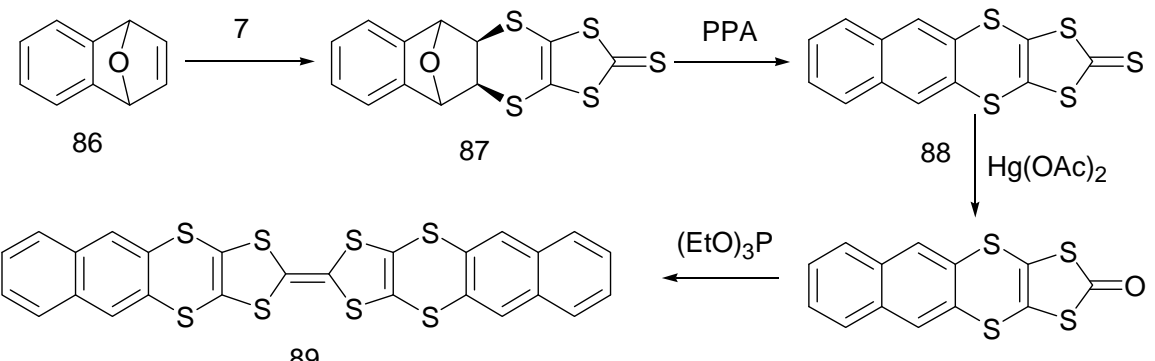

Scheme 10

ETs fused to pyrazines, quinoxalines and pyridopyrazines have been prepared by nucleophilic substitution of 2,3-dihalo-heterocycles by dithiolate 5 followed by standard 
coupling procedures ${ }^{53}$ (Scheme 11). Some of these donors have very low solubilities in common solvents.

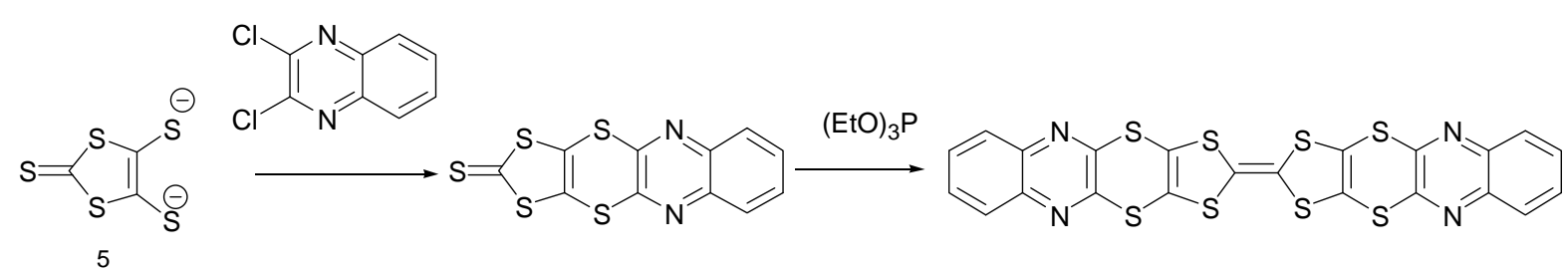

Scheme 11

\section{Halo-substituted ET derivatives}

The synthesis of halo-functionalised ET systems is an area of interest for two reasons. Intermolecular interactions between halo substituents on an organosulfur donor can play a significant role in organising the solid state structures of the radical cation salts, leading to novel packing modes. ${ }^{54}$ Furthermore, nucleophilic substitutions of a donor's halo substituents can lead to the rapid production of many new derivatives. Fourmigué prepared the mono- and trans-di-chloro substituted oxo compounds $\mathbf{9 1}$ and 92 in very good yields by treatment of the unsubstituted oxo compound $\mathbf{9 0}$ with one or two equivalents of sulfuryl chloride in carbon tetrachloride. ${ }^{55}$ Homocoupling of oxo compounds gave the di- and tetra-chloro functionalised ET derivatives 94 and 95 as mixtures of isomers in high yields (Scheme 12). ${ }^{56}$ Electrocrystallisation of the tetrachloro donor 95 with the $\mathrm{Mo}_{6} \mathrm{Cl}_{14}{ }^{2-}$ dianion gave a 3:1 salt, in which a centrosymmetric meso donor with axial trans chloro groups on each ethylene bridge is sandwiched between two disordered donors which are twisted in their TTF planes with respect to the central donor to avoid steric interactions between their chlorine substituents. The outer molecules carry most of the cationic charge. Katsuhara has reported semiconducting 1:1 radical cation salts of the tetrachloro donor 95 with $\mathrm{AsF}_{6}{ }^{-}$and $\mathrm{ClO}_{4}{ }^{-57}$ and again the chlorines adopt axial positions. The cation and anion alternate in a pseudo $\mathrm{NaCl}$ structure in the $\mathrm{AsF}_{6}{ }^{-}$ salt, while the $\mathrm{ClO}_{4}{ }^{-}$salt is strongly one dimensional. The cross coupled dichloro donor 96 is also reported. ${ }^{57}$ Fourmigué also reports the monofluorination of oxo compound 90 to give 93 using either ${ }^{\circledR}$ Selectfluor or xenon difluoride, the latter method producing a superior yield $(80 \%) .{ }^{56}$ Homocoupling in trimethyl phosphite gave the di-fluorinated ET 97 as a mixture of isomers. 


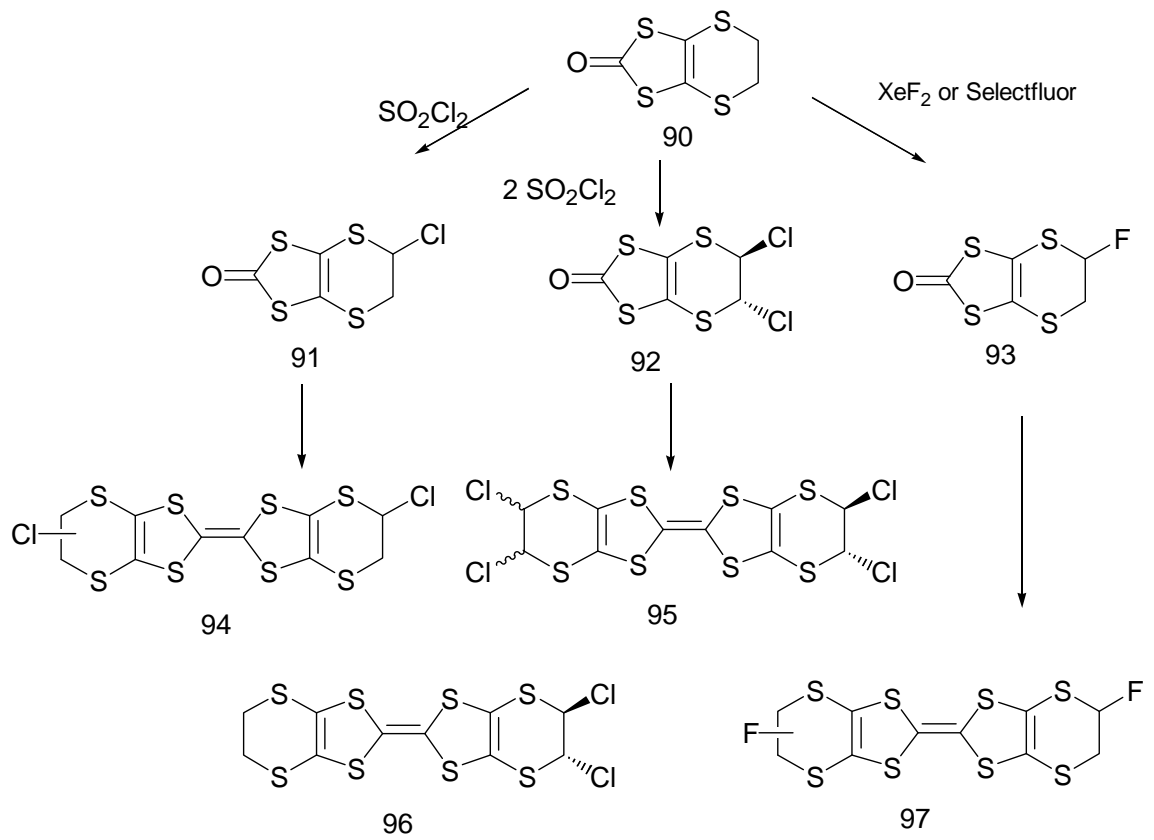

Scheme 12

An isomeric mixture of ETs, disubstituted with two chloromethyl groups, 102, was prepared by Kumar by homocoupling of the chloromethyl substituted thione 99. This was prepared from the hydroxymethyl thione $\mathbf{9 8}$ and thionyl chloride in pyridine, ${ }^{58}$ and the isomeric chloro-thione with an outer seven membered ring 101 was also produced, probably via the fused thiiranium salt 100 (Scheme 13). The bromomethyl thione has been prepared from trithione 7 and allyl bromide. ${ }^{41}$

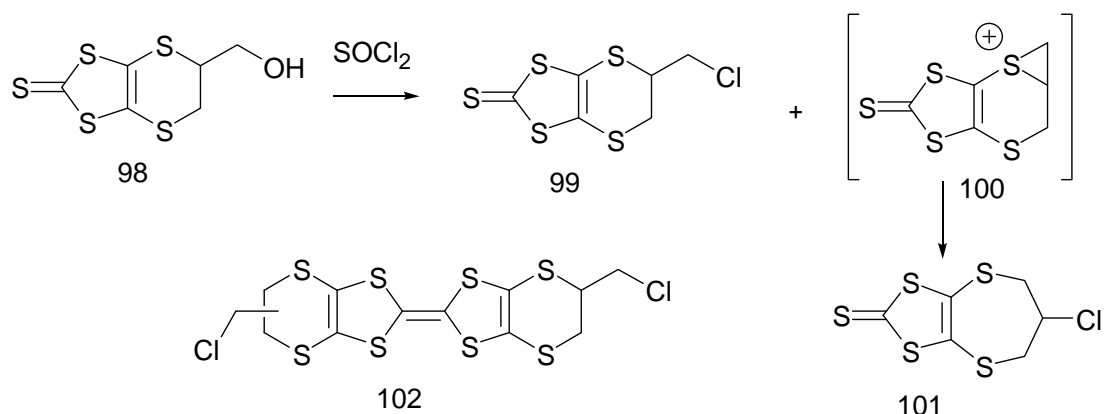

Scheme 13

An attempt to prepare the enantiopure trans bis(fluoromethyl) thione by a double substitution reaction of the cyclic sulfate ester 103 by the dithiolate 5 led instead to the thione containing a 2-fluoro-1-hydroxyethyl sidechain 104, which could be converted in two steps to the monosubstituted ET 105 (Scheme 14). ${ }^{59}$ After ring opening of cyclic sulfate ester 103 by the dithiolate, the remaining thiolate group surprisingly displaces the nearer fluoride rather than sulfate ion. Note it was possible to carry out the 
heterocoupling reaction without protection of the hydroxyl group which is not usually the case.

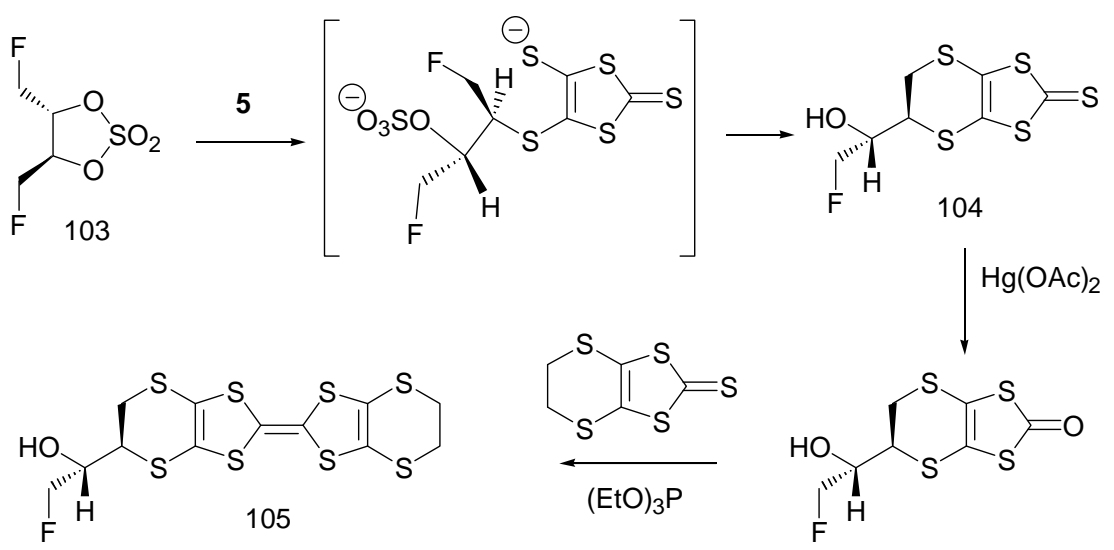

Scheme 14

\section{Hydroxy and ether functionalised ET derivatives}

Hydroxymethyl-ET, HMET, 108, is most readily prepared in four steps with an overall yield $15 \%$, starting from reaction of the trithione 7 with allyl acetate to give thione $\mathbf{1 0 6}^{24}$ (Scheme 15), followed by S/O exchange, cross coupling with unsubstituted thione $\mathbf{9}$ and hydrolysis of the acetate group. Zhu has prepared HMET in a similar way, starting from allyl alcohol and $\mathbf{7}$ to give 107, ${ }^{60,61}$ while an earlier route involved reaction of dithiolate 5 with O-protected 2,3-dibromopropanol. ${ }^{14}$ Electrocrystallisation of HMET led to semiconducting, microcrystalline 2:1 radical cations with $\mathrm{BF}_{4}^{-}, \mathrm{Cl}^{-}, \mathrm{PF}_{6}^{-14}$ and $\mathrm{ClO}_{4}{ }^{-}{ }^{60}$ Wallis prepared enantiopure HMET via reaction of the dithiolate 5 with the OMEM protected cyclic sulfate ester 109, prepared from $D$-mannitol in six steps, to give enantiopure thione $\mathbf{1 1 0}$ in 54\% yield which was converted to the O-MEM-protected donor $\mathbf{1 1 1}$ in the normal way, and finally deprotected with $20 \%$ hydrochloric acid/THF to give the $R$ enantiomer of HMET. ${ }^{62}$ Note the cyclic sulfate ester 109 needs to be used soon after preparation, since it is prone to decomposition. The O-benzoyl analogue rearranges quantitatively to the six-membered cyclic sulfate ester 112, with intramolecular ring opening of the cyclic sulfate ester as the likely starting point (Scheme $16)^{62}$ 


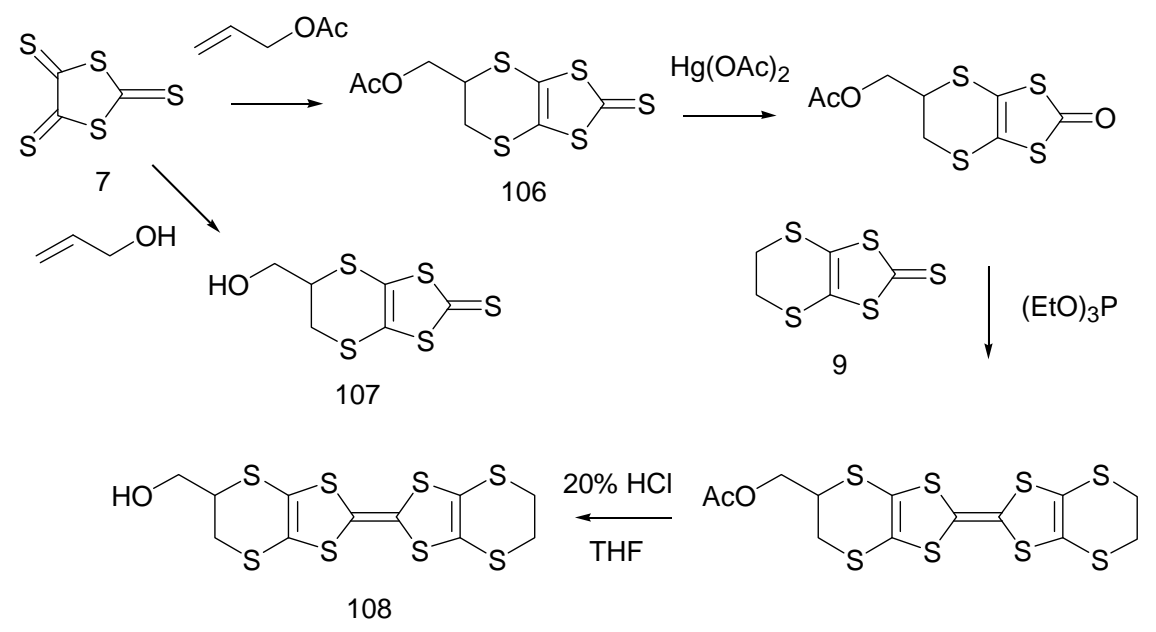

Scheme 15
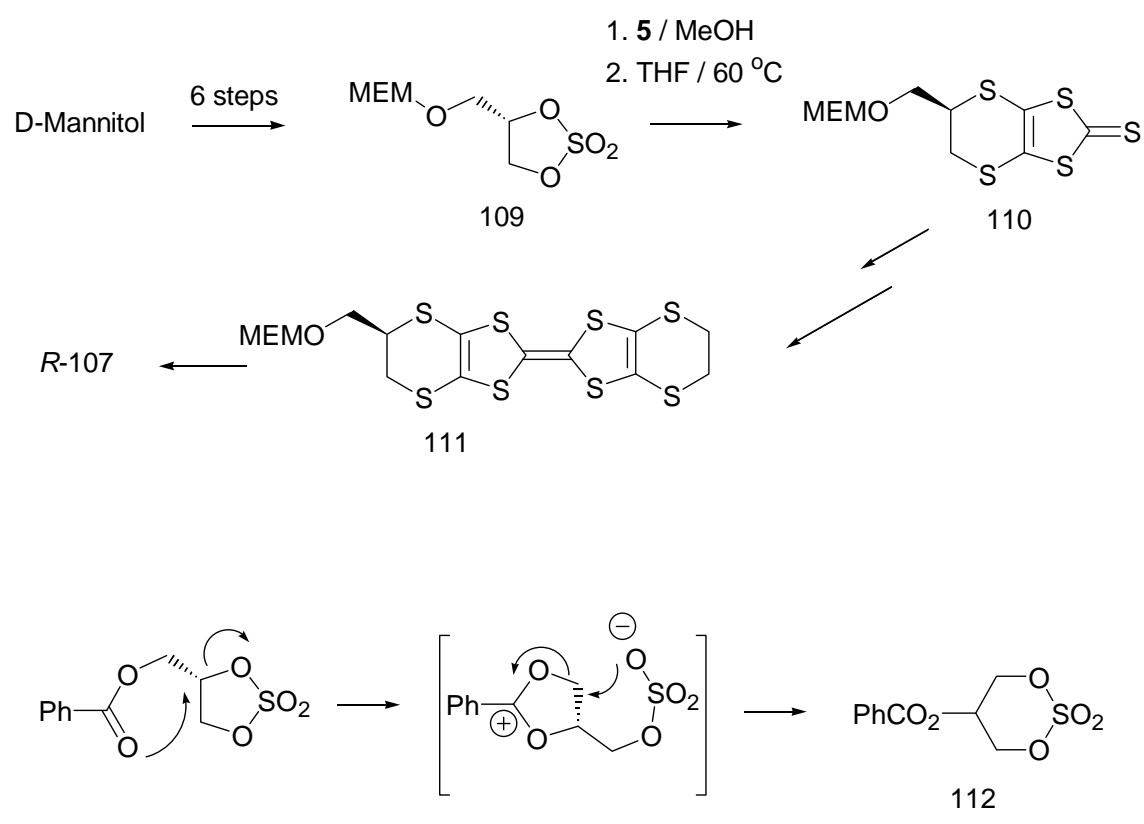

Scheme 16

Cycloaddition reactions of trithione 7 with but-3-en-1-ol and cis or trans but-2en-1,4-diol have led to the hydroxyethyl ${ }^{24,63}$ and cis $^{60}$ and trans $^{24}$ bis(hydroxymethyl) thiones 113-115 respectively. After $O$-protection with acetyl or t-butyldiphenylsilyl groups, the synthetic plan outlined in Scheme 15 led to hydroxyethyl-ET (HEET) $\mathbf{1 1 6}^{24,63}$ and the cis and trans isomers of bis(hydroxymethyl)ET 117-118. ${ }^{24,60} \mathrm{Zhu}$ has structurally characterized a semiconducting 2:1 radical cation salt of the cis-diol 117 with chloride. ${ }^{60}$ The anion is hydrogen bonded to three hydroxyl groups from different donor molecules (Fig. 4). Donors are arranged in stacks with substituents directed alternately to opposites sides of the stack. Chinese workers have reported the acetyl protected hydroxymethyl- and hydroxypropyl thiones 105 and 119 and their conversion to homocoupled di(hydroxyalkyl) donors as mixtures of stereoisomers. ${ }^{64}$ 


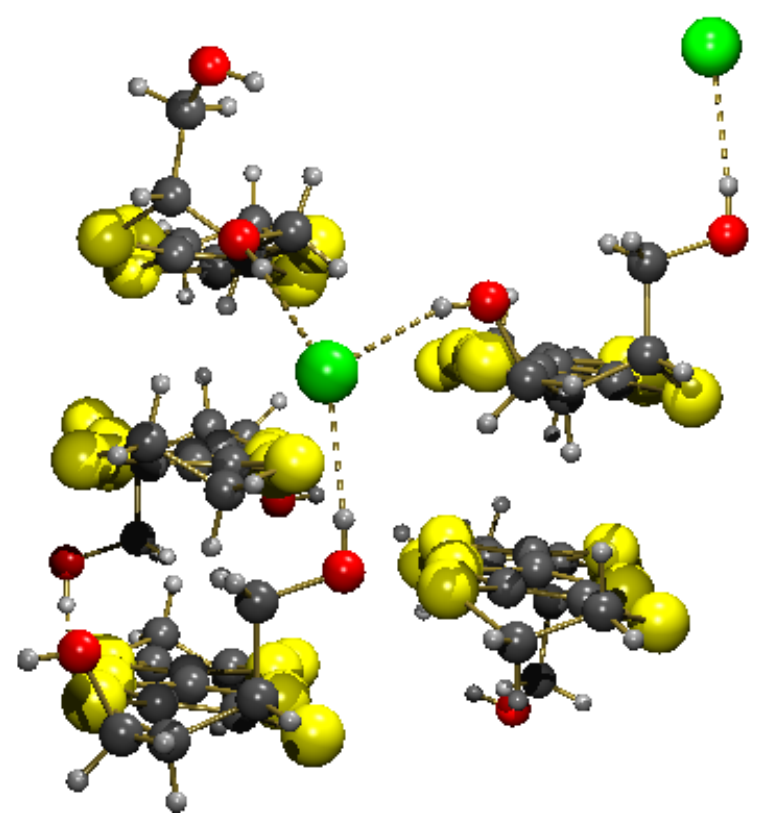

Figure 4: Hydrogen bonding of a chloride ion to three donor molecules in (cis-bis(hydroxymethyl)ET) ${ }_{2} \mathrm{Cl}^{60}$<smiles>OCCC1CSc2sc(=S)sc2S1</smiles>

113<smiles>OCC1Sc2sc(=S)sc2SC1CO</smiles>

114<smiles>OCC1Sc2sc(=S)sc2S[C@@H]1CO</smiles>

115<smiles>OCCC1CSC2=C(SC(=C3SC4=C(SCCS4)S3)S2)S1</smiles><smiles>CCC1SC2=C(SC(=C3SC4=C(SCCS4)S3)S2)SC1CO</smiles><smiles>OCC1SC2=C(SC(=C3SC4=C(SCCS4)S3)S2)SC1CO</smiles>

118<smiles>[R]OCC1CSC2=C(SC(=C3SC4=C(SCCS4)S3)S2)S1</smiles>

$120 \mathrm{R}=\mathrm{Me}$

$121 \mathrm{R}=\mathrm{Et}$<smiles></smiles>

119

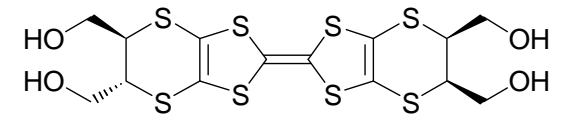

43

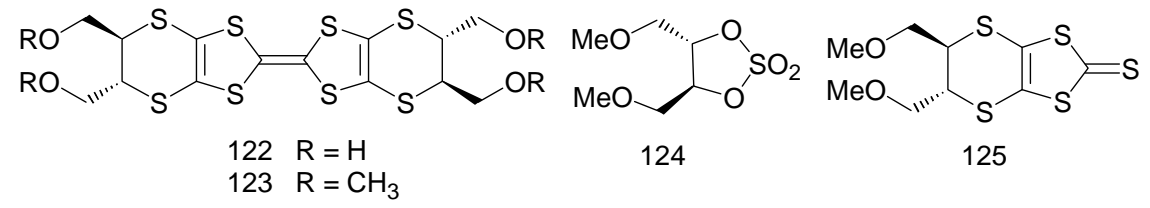


The cross coupling of cis and trans thiones to the racemic cis, trans tetra(hydroxymethyl)-ET $\mathbf{4 3}$ has been referred to earlier (Scheme 5), ${ }^{24}$ while other reported preparations of tetra(hydroxymethyl))-ET provided mixtures of stereoisomers. ${ }^{65}$ Future access to the enantiopure form of the trans bis(hydroxymethyl)thione $\mathbf{1 1 5}$ is the key to preparing the all-trans enantiopure donor 122.

Tosylations of the hydroxy-substituted thione 106 and the donor HEET 116 have been used in further synthetic elaborations to introduce further functionalities by nucleophilic substitutions. ${ }^{63}$ Ether links have been installed early in donor synthesis, in lieu of $O$-protection, for example in the preparation of 120 and $\mathbf{1 2 1},{ }^{14}$ but could be installed at the end if the grouping to be attached is difficult or expensive to prepare. Wallis has prepared the enantiopure tetra(methoxymethyl)ET 123 from cyclic sulfate ester 124 and dithiolate 5 to give thione 125 followed by standard transformations. ${ }^{14}$ However, the cyclisation reaction with 5 is very low yielding ( $c$ a 5\%), and this is typical of cyclic sulfate esters with two bulky substituents.

A further class of extended donor involves fusion of one or two 1,4-dioxane rings by ether links to the ethylene bridges of ET, e.g. symmetrical donor $\mathbf{1 2 9}$ where there is cis fusion between heterocyclic rings, but there are two stereoisomers due to the relative dispositions of the two dioxane rings. The cis-fused thione 127 is prepared by cycloaddition of trithione 7 with 1,4-dioxene, ${ }^{66}$ or via reaction of 2,3-dichloro-1,4dioxane with either the zinc salt of dithiolate $5^{67}$ or with its dibutyltin derivative 126 under boron trifluoride catalysis. ${ }^{68}$ The thione can be converted in two steps to donors 128 (DOET) and 129 which has both syn and anti stereoisomers. Radical cation salts $(\mathbf{1 2 8})_{2} \mathrm{Au}(\mathrm{CN})_{2}$ and $(\mathbf{1 2 8})_{2} \mathrm{BF}_{4}$ show metallic behaviour with room temperature conductivities ca. 10-30 S cm${ }^{-1}$ and $(\mathbf{1 2 8})_{4} \mathrm{Hg}_{2} \mathrm{Cl}_{6}$ remains metallic down to $4 \mathrm{~K}^{69,70} \mathrm{~A}$ range of salts of the syn isomer of the bis fused donor $\mathbf{1 2 9}$ have been reported as well as a triiodide salt of anti isomer of this donor. ${ }^{67,71}$ It is notable that the dioxane rings lie roughly at right angles to the plane of the organosulfur system, but they do not prevent stacking of the organosulfur donors (Fig. 5). Syntheses of the "all sulfur" analogues of 128 and 129 have been reported, ${ }^{68}$ and a "mixed system" has been prepared from 2,3dihydro-1,4-oxathiine, but the relative positions of the $\mathrm{O}$ and $\mathrm{S}$ atoms in the outer rings leads to a larger mixture of stereoisomers. ${ }^{72}$ ET donors fused to one or two tetrahydrofuran rings have been prepared from 2,5-dihydrofuran, and a range of radical cation salts characterized. ${ }^{73}$ 

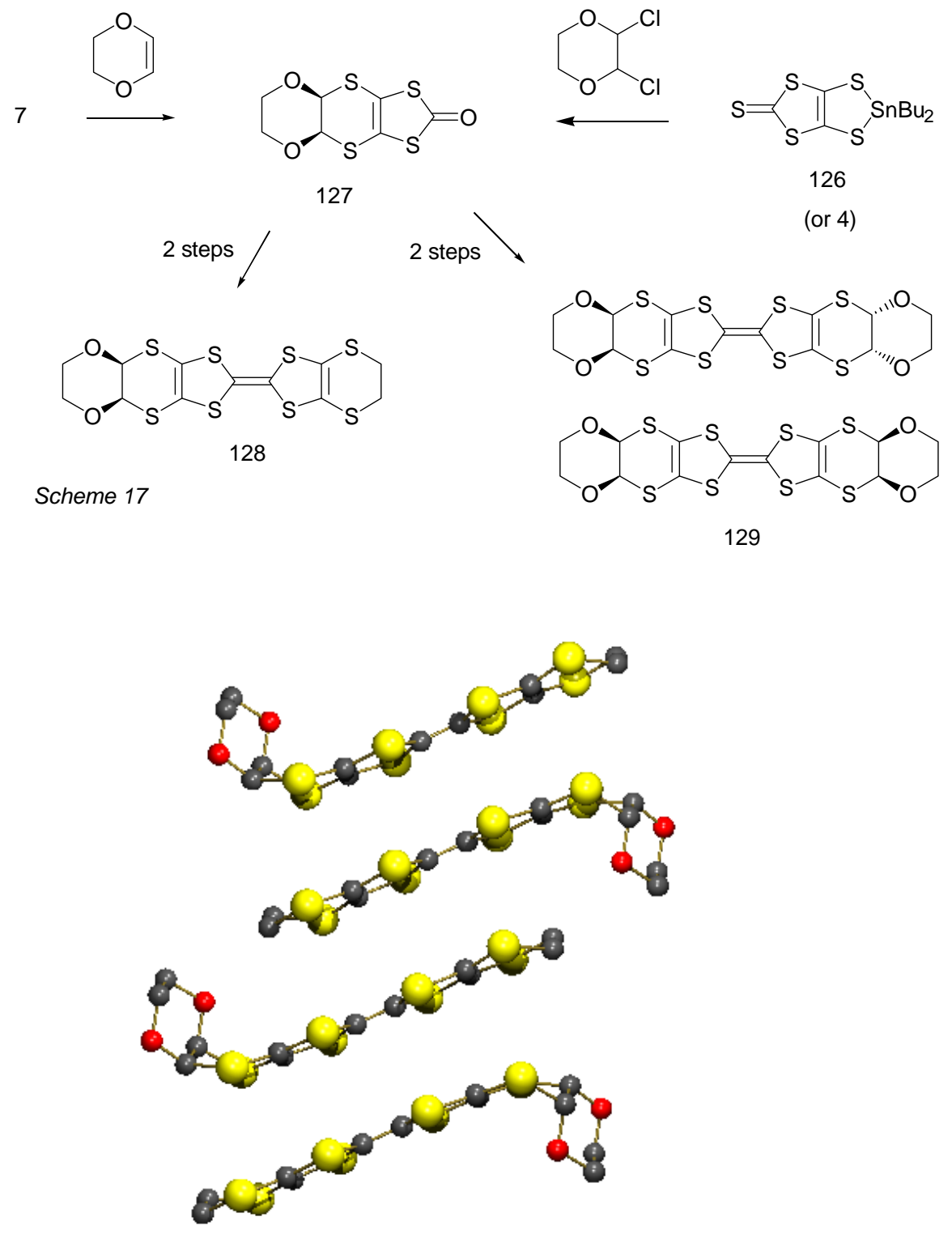

Figure 5. Stacking of donor molecules in $(\mathrm{DOET})_{2} \mathrm{BF}_{4}{ }^{69}$

\section{Amino functionalised ET derivatives}

Amino groups are ideal functionalities for attachment of further structural components. Wallis prepared aminomethyl-ET, AMET, 133 by the initial ring closure of $\mathrm{N}$-Boc-allylamine with the trithione 7 in refluxing toluene to give thione 130. Subsequent sulfur/oxygen exchange and triethyl phosphite mediated cross coupling with the unsubstituted thione 9 produced $N$-Boc-aminomethyl-ET 131. Deprotection using TFA furnished the AMET trifluoroacetate salt 132, which could be deprotonated to obtain the free amine, AMET 133 (Scheme 18). ${ }^{74}$ The amino group underwent DCC mediated coupling to give amide containing systems e.g. 137, but did not react with acyl chlorides or sulfonyl chlorides. Furthermore, carboxylic amides can be prepared by mixed anhydride methods using tosyl chloride, e.g. the trifluoroacetyl derivative 134 from 132 
the TFA salt of AMET, and the isopicolinyl derivative 135 from AMET and isonicotinic acid. Reaction with 2,5-diethoxy-THF led to installation of a pyrrole group in 136. $^{74}$
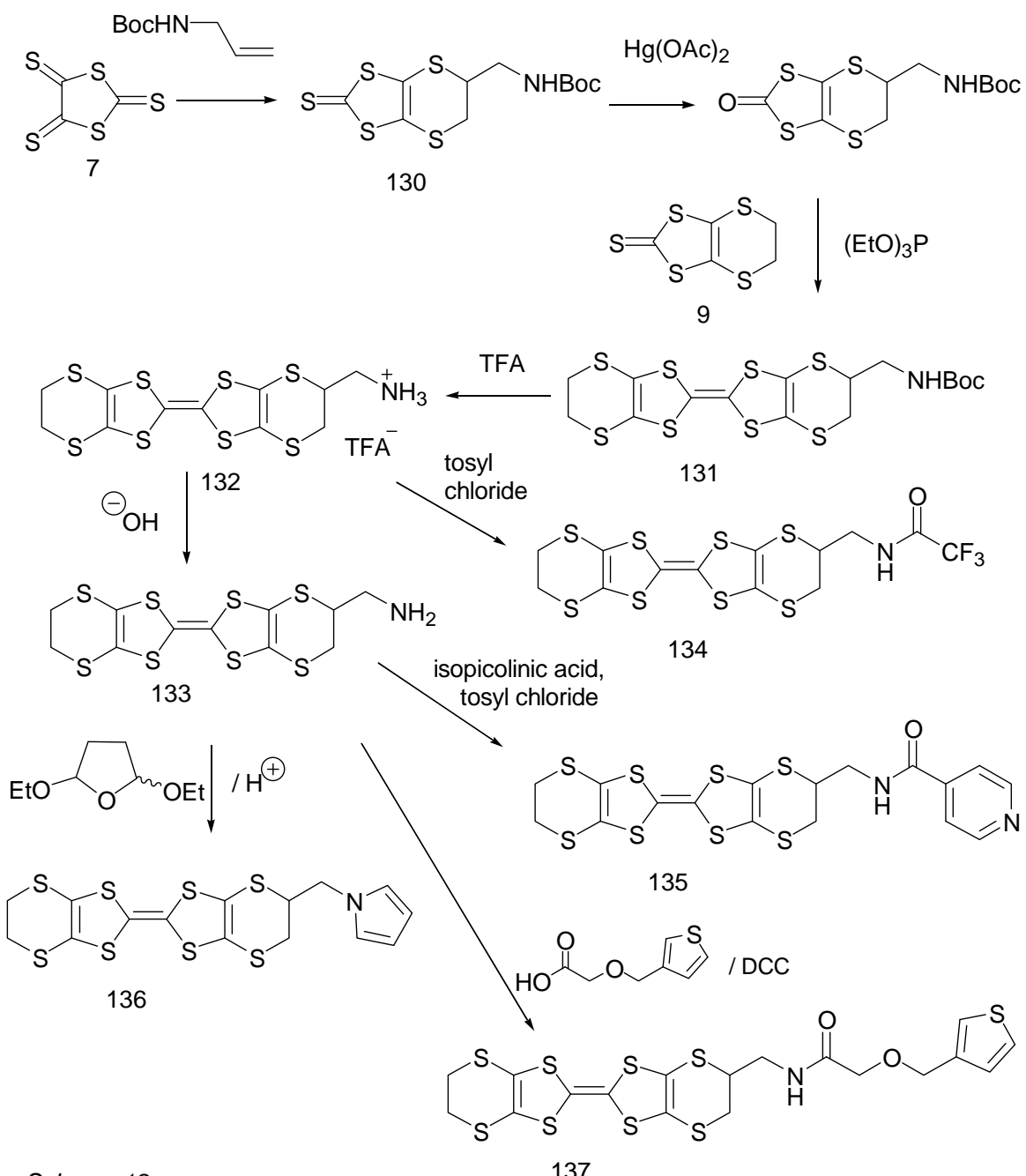

Scheme 18

Aminoethyl-ET, AEET, 140 was prepared by ring closure of allyl cyanide with trithione 7, to give thione 138 followed by sulfur/oxygen exchange and heterocoupling with unsubstituted thione 9 to yield the cyanomethyl-ET 139. Reduction with $\mathrm{LiAlH}_{4}$ gave the amine AEET 140 (Scheme 19). ${ }^{74}$ In contrast to AMET, AEET reacts with tosyl chloride to furnish a sulfonamide 141. 


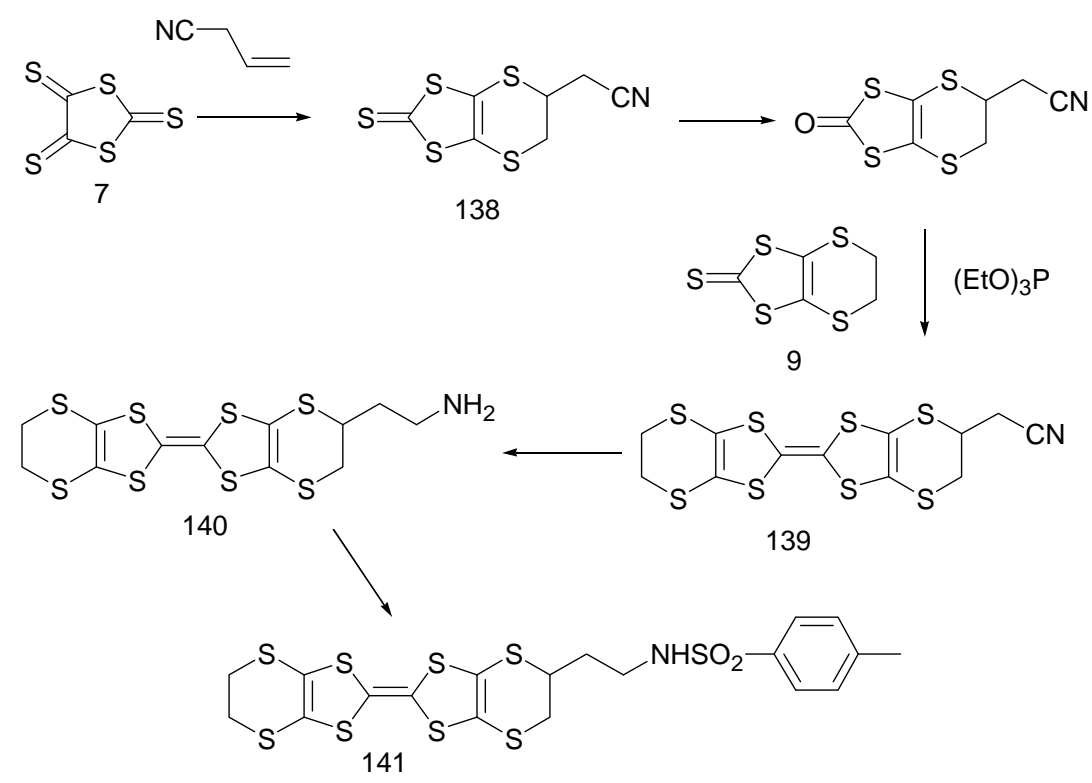

Scheme 19

Kumar et al. prepared dicyano-ET 143 as a mixture of isomers, by reaction of TTFtetrathiolate with 2,3-dibromopropionitrile since homocoupling of the thione 142 using trimethyl or triethyl phosphite or dicobalt octacarbonyl was unsuccessful. ${ }^{58}$

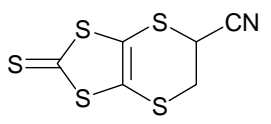

142

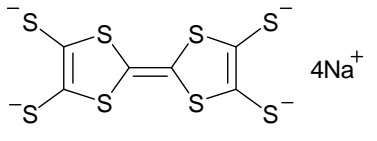

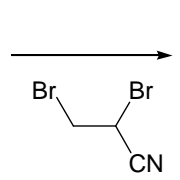

\section{Carbonyl containing ET derivatives}

There are only a few references to ET derivatives with ester carbonyl functionalities directly attached to the molecular skeleton. ${ }^{27,75}$ The corresponding thione building blocks such as $\mathbf{1 4 4} 4^{18,75}$ and $\mathbf{1 4 5} 5^{18,76}$ are known, the former is reported to have been homocoupled ${ }^{75}$ but the latter undergo Arbusov reactions with triethyl phosphite. ${ }^{76}$ The acetal protected derivatives 148 and 149 of the ET-aldehyde 150 have been prepared from thiones 146 and 147 which are available from the dithiolate 5 and the corresponding vic-dibromides, but attempts to deprotect them have failed so far. ${ }^{14}$ The expected aldehyde $\mathbf{1 5 0}$ may be vulnerable to hydrolytic cleavage of the C-S bond at the stereogenic centre and others have reported difficulties in hydrolysing ketals on organosulfur systems ${ }^{77}$ Hence, most compounds known contain a methylene group between the ET and carbonyl functionality. Thus, Wallis prepared methyl ET-ethanoate 13 via reaction of the dithiolate $\mathbf{5}$ with the corresponding vic-dibromide to yield the thione $\mathbf{1 5 1}$ which is converted by standard methods to the donor. Thus, the racemic material is available from vinyl acetic acid in five steps, with just one chromatographic purification at the cross coupling step. ${ }^{16}$ The enantiopure form, $R-13$ was prepared analogously using the cyclic sulfate ester 152 in place of the vic-dibromide. ${ }^{17}$ In contrast, it has been found preferable 
to install amide functionality early in the synthesis. Thus, the carboxylic acid bearing thione 153, prepared from trithione 7 and acrylic acid, is converted to a range of amides 154-158 by mixed anhydride technology and the products transformed to monosubstituted ET derivatives 159-163. ${ }^{16}$ Indeed, these compounds are of particular interest since they have potential for hydrogen bonding playing an important role in the ordering of their radical cation salts, as has been observed in other systems. ${ }^{78}$ The c.v. data for the esters and amides are typical for ET derivatives and several radical cation salts of the amides have been prepared.

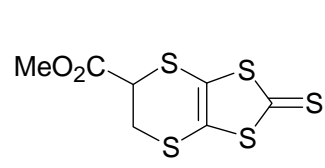

144

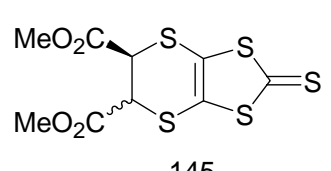

145

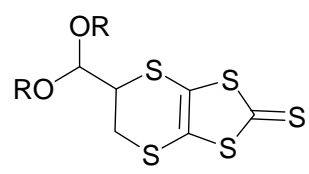

$146 \mathrm{R}=\mathrm{Me}$

$147 \mathrm{R}, \mathrm{R}=-\mathrm{CH}_{2} \mathrm{CH}_{2}$<smiles>[R]OC([R2])C1CSC2=C(SC(=C3SC4=C(SCCS4)S3)S2)SC1C(=O)[CH][Y](C)C</smiles>

$148 \mathrm{R}=\mathrm{Me}$

$149 \mathrm{R}, \mathrm{R}=-\mathrm{CH}_{2} \mathrm{CH}_{2}-$

150

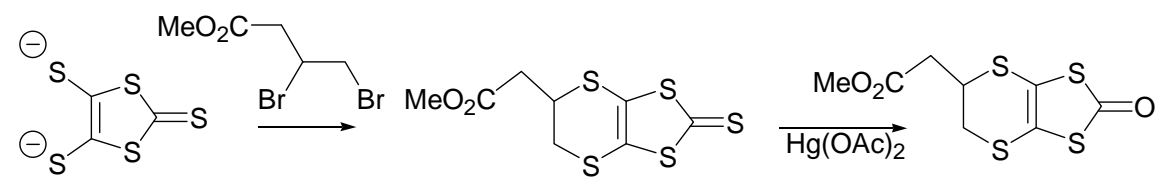

151<smiles></smiles>

152

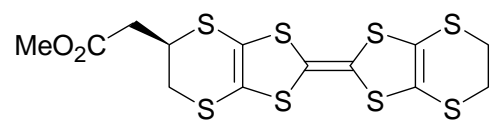

13

Scheme 20

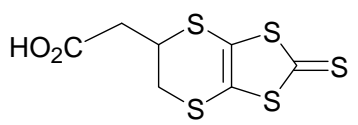<smiles>[R]NC(=O)CC1CSc2sc(=S)sc2S1</smiles>

$154 \mathrm{R}=\mathrm{H} ; 157=2$-pyridyl

$155 \mathrm{R}=\mathrm{Et} ; 158=4-\mathrm{HOC}_{6} \mathrm{H}_{4}$

153<smiles>[R]NC(=O)CC1CSC2=C(SC(=C3SC4=C(SCCS4)S3)S2)S1</smiles>

$159 \mathrm{R}=\mathrm{H} ; 162=$ 2-pyridyl

$160 \mathrm{R}=\mathrm{Et} ; 163=4-\mathrm{HOC}_{6} \mathrm{H}_{4}$

$161 \mathrm{R}=\mathrm{Ph}$ 


\section{ET analogues with expanded outer rings}

The ET analogues with one or two extra methylene units in the outer rings, $\mathbf{1 6 4}^{79}$ and $\mathbf{1 6 5},{ }^{80,81}$ are well documented, and their first oxidation potentials are very similar

those of ET. ${ }^{82}$ The synthetic approaches to substituted analogues is via the corresponding thiones. For the seven-membered ring series Bryce and others ${ }^{77,83}$ prepared the ketothione 166, and transformed it to the bis(keto) donor 168, protecting the carbonyl group with a cyclic ketal as $\mathbf{1 6 7}$ before the coupling step with triethyl phosphite. The structure of donor $\mathbf{1 6 8}$ has been measured, ${ }^{84}$ and a 1:1 salt with $\mathrm{IBr}_{2}{ }^{-}$has been characterized. ${ }^{84,85}$ Imines, oximes and hydrazides of donor 168 have been reported. ${ }^{83}$ Reduction of ketothione $\mathbf{1 6 6}$ to the hydroxyl-thione 169, O-protection with t-butyldiphenylsilyl, homocoupling and finally deprotection led to the dihydroxy donor $\mathbf{1 7 0}$ as a mixture of cis and trans isomers, ${ }^{77,83}$ which has been used as a building block for the constructions of a copper(I) centred [2]catenane ${ }^{86}$ and [2]pseudorotaxanes and [2]catenanes which contain charge transfer interactions between the organosulfur system and a tetracationic bis(paraquat-p-phenylene) ring. ${ }^{87}$ It was demonstrated that on electrochemical oxidation a [2]pseudorotaxane separates into its two components with the loss of the charge transfer interaction. The hydroxyl-thione $\mathbf{1 6 9}$ is also obtained by reaction of the dithiolate $\mathbf{5}$ with 1,3-dichloropropan-2-ol, ${ }^{77}$ and also with 2,3-dibromopropan-1-ol. ${ }^{58}$ In the latter case, initial substitution of the primary bromide is probably followed by base catalysed epoxide formation and subsequent ring opening by the second thiolate. In contrast the zinc complex of the dithiolate, $\mathbf{4}$, formed the six-membered ring 171. 

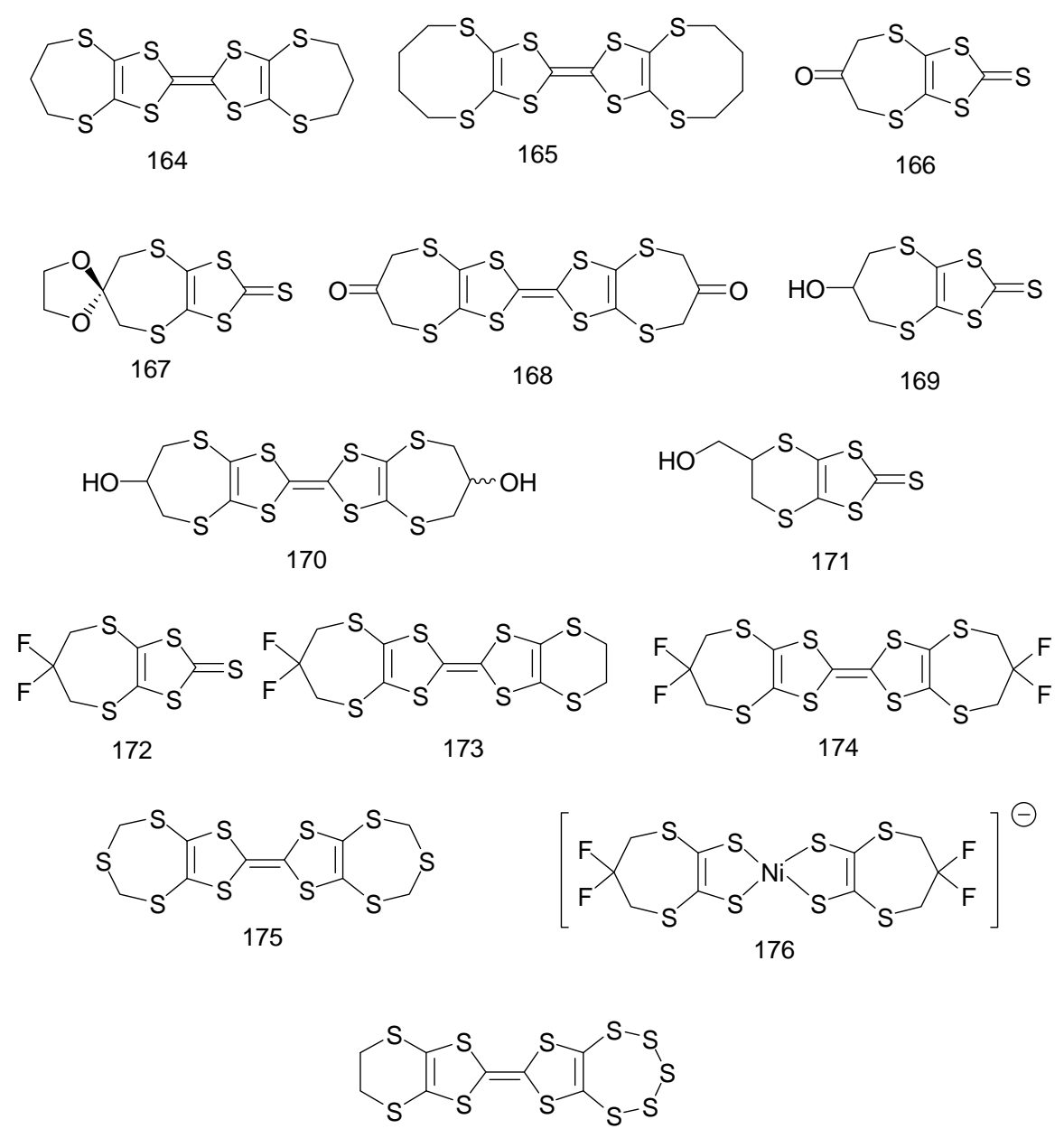

177

Fourmigué replaced the oxygen of keto-thione 166 with two fluorines using DAST giving thione 172 and converted it to difluoro and tetrafluoro donors 173 and 174, resulting in small increases in first oxidation potentials, e.g. by $0.13 \mathrm{~V}$ for $\mathbf{1 7 4}$ over its unfluorinated analogue 164. ${ }^{88} 1: 1$ Salts of tetrafluoro donor 174 with $\mathrm{ICl}_{2}^{-}, \mathrm{IBr}_{2}^{-}$and $\mathrm{I}_{2} \mathrm{Br}^{-}$have most remarkable structures with the linear anion lying above the donor which acts as a "molecular pincer" holding the anion by hydrogen bonding with one methylene group at each end of the donor (Fig. 6). ${ }^{89,90}$ (A similar mode of association has been observed for the $\mathrm{IBr}_{2}{ }^{-}$salt of the bis(1,4,6-trithiepinyl)TTF $\mathbf{1 7 5}{ }^{81,85}$ ) The adjacent fluorines and the donor's positive charge promote the hydrogen bonding potential of the methylene groups. Furthermore, the packing arrangement is influenced by fluorine segregation giving a fluorous interface between layers including also some short $\mathrm{H}---\mathrm{F}$ contacts. In the 2:1 salt of 174 with $\mathrm{Mo}_{6} \mathrm{Cl}_{14}{ }^{2-}$ two donors act as pincers forming hydrogen bonds to chlorines of the complex anion. ${ }^{89,90}$ Fourmigué has also described an interesting 1:2 mixed valence salt of $\mathbf{1 7 4}$ with the isosteric dithiolene anion 176, ${ }^{91}$ and a 1:1 charge transfer salt of the difluoro donor $\mathbf{1 7 3}$ with $\mathrm{TCNQF}_{4}$ has been described in which pairs of donors and pairs of acceptors form a pseudo $\kappa$-phase. ${ }^{92}$ Donor 177 which has five sulfur atoms in an outer seven membered ring has been reported along with its perchlorate salt. $^{93}$ 


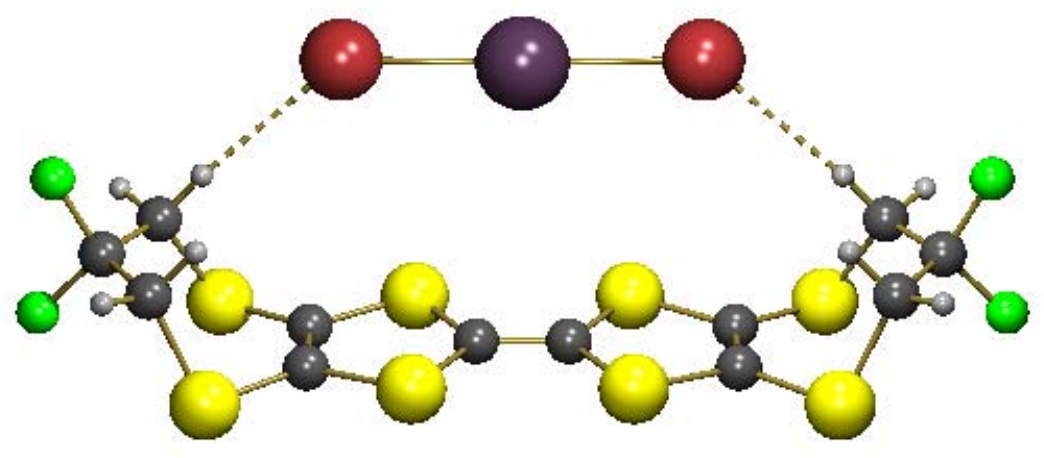

Figure 6. Donor 174 acts as a pincer holding a $\mathrm{IBr}_{2}^{-}$anion by hydrogen bonding. ${ }^{89,90}$

The Wallis group prepared achiral bis(hydroxymethyl)thione $\mathbf{1 7 8}$ in lowish yields (ca. 25\%) by reaction of the dithiolate 5 with either 2,2-bis(bromomethyl)propane-1,3diol or with the bis cyclic sulfate ester of pentaerythritol followed by hydrolysis. The hydroxyl groups were protected with MEM groups and the symmetrical donor 179 was constructed by standard procedures. ${ }^{23}$ Unsymmetrical bis- and tris(hydroxymethyl) donors 180-181 and 39, the latter in both racemic and enantiopure forms, have been prepared by cross coupling reactions, ${ }^{23,94}$ and a $2: 1$ triodide salt of the bis(hydroxymethyl) donor $\mathbf{1 8 0}$ has been structurally characterized. ${ }^{95}$ Pairs of donors are packed into a pseudo $\kappa$-phase layer, with hydroxymethyl substituents directed to both faces of the layer where they hydrogen bond with the hydroxyl groups of the next layer. Pairs of triiodides sit in pockets between layers. The seven-membered ring adopts a pseudo chair structure with the three $\mathrm{sp}^{3} \mathrm{C}$ atoms displaced to the same side of the molecular plane, as observed for thione $\mathbf{1 6 9}^{58,77}$ and the tetrafluoro donor $\mathbf{1 7 4} .^{88}$ Nevertheless, some flexibility is available since in neutral 180 the ring adopts a pseudo half chair conformation with the methylene groups displaced to opposite sides of the molecular plane. ${ }^{95}$ 


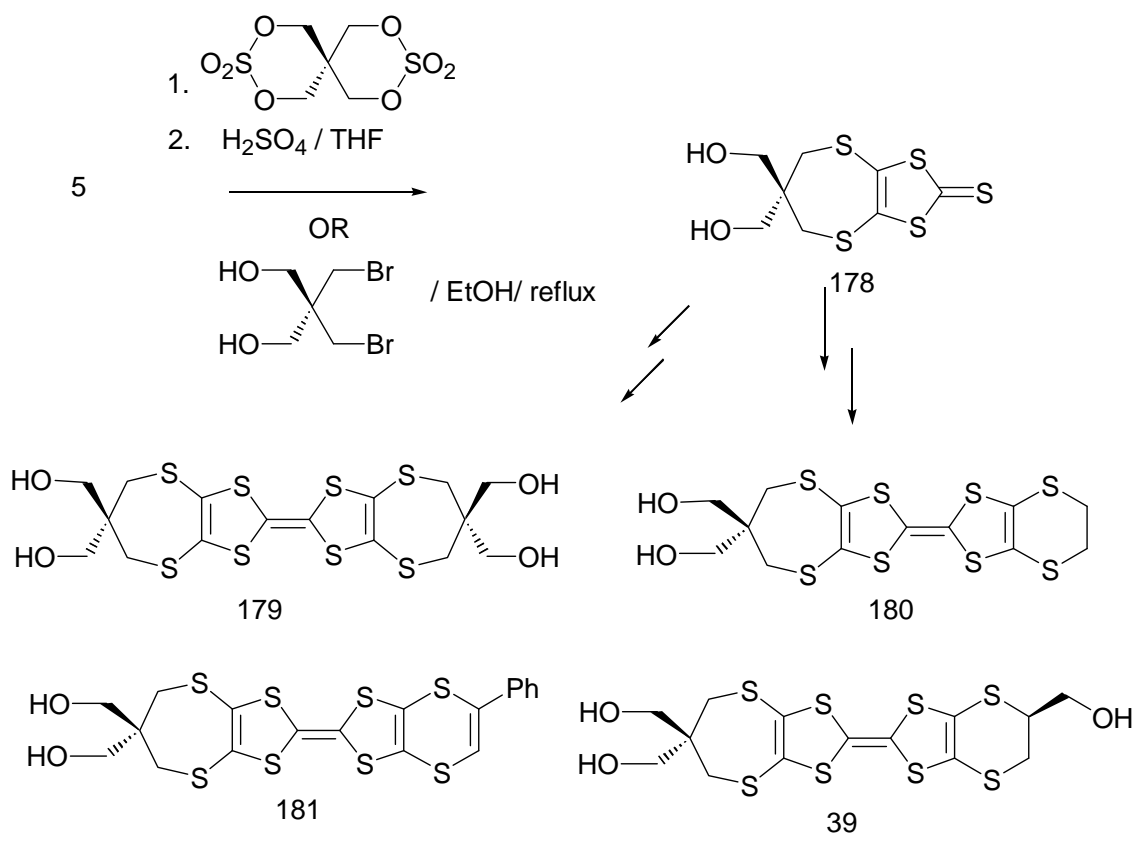

Scheme 21

Enantiopure donors 185 and 186, with one or two outer eight membered rings containing two hydroxyl groups, have been prepared from the thione $\mathbf{1 8 3},{ }^{96}$ available from dithiolate 5 and the O-MEM protected diodide 182. Although one MEM group is mainly lost in the sulfur/oxygen exchange reaction with mercuric acetate in chloroform and acetic acid, the resultant oxo compound 184 could be self coupled or cross coupled and then deprotected to produce the donors. It is notable that the ketal protected bis tosylate 187 forms thione 188 on reaction with dithiolate 5, and can be converted in two steps to the donor 189, but the two ketal groups could not be successfully removed to give tetrol 185. X-ray structures of thione $\mathbf{1 8 8}^{96}$ and the corresponding oxo compound ${ }^{97}$ show that all four carbon atoms of the butylene bridge lies to one side of the planar sulfur system, with a twist enforced by the fusion of the dioxolane ring.
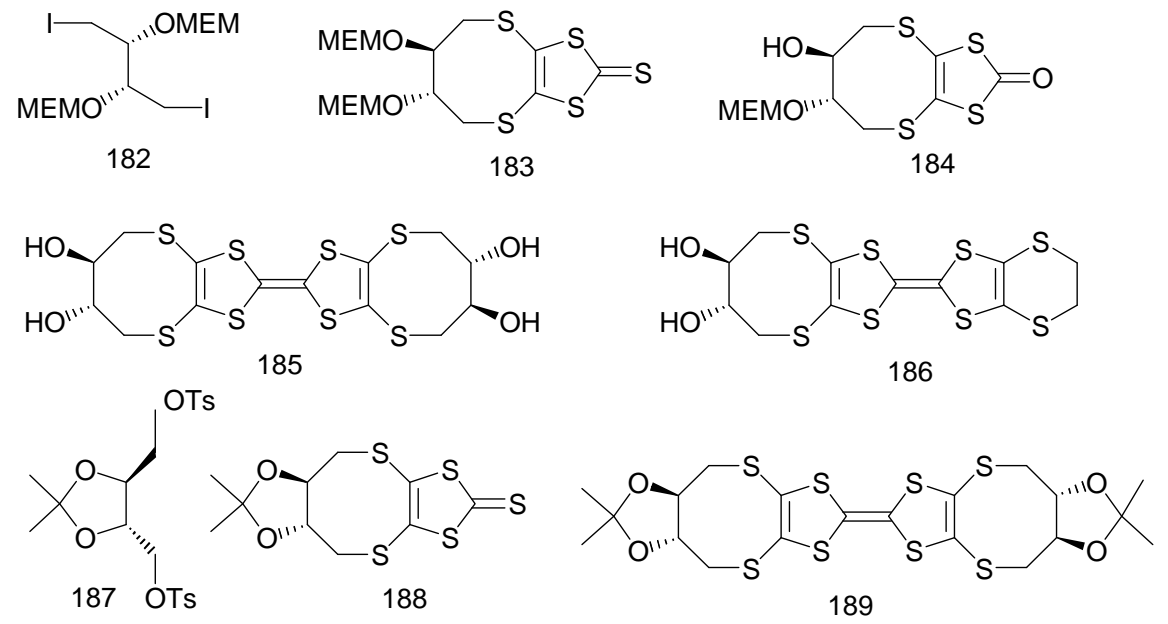


\section{Enantiopure ET systems.}

The question of whether the sense of chirality has an effect on the electrical properties of a material, has been posed by Dunitz and others, but has not to date been deeply investigated due to lack of suitable enantiopure materials. Rikken has, however, recently demonstrated magnetochiral anisotropy in carbon nanotubes with a chiral surface when the magnetic field is coaxial with the nanotube. ${ }^{9}$ Radical cation salts of enantiopure donors are expected to suffer less from structural disorder than those of racemates where, in some cases at least, the crystal structure may tolerate the enantiomers exchanging places. Dunitz and Hilti ${ }^{29}$ reported the first radical cation salts of an enantiopure donor using S,S,S,S-TMET 52, though the crystal packings were pseudo-centrosymmetric. Salts of enantiopure dimethyl-ET, 16 are known. ${ }^{33-35}$ The reaction of dithiolate 5 with enantiopure cyclic sulfate esters have been used to prepare donors 13 and 107 referred to above. However, diastereoselective hetero Diels Alder reactions of the trithione 7 provide an opportunity for preparing further enantiopure donors. Thus, Wallis found that 7 reacts with total diastereoselectivity and in high yield with (-)-carene, (-)- $\alpha$-pinene, and (-)- $\beta$-pinene by attack on the less hindered face of the terpenoid alkene to give thiones 190-192. ${ }^{17}$ Thione 192 was converted to its oxo compound and cross coupled with the unsubstituted thione 9 to give the enantiopure donor 193, and homocoupled to give donor 194 as a mixture of two diastereoisomers (Scheme 22). Thione 191 is particularly strained, showing a C-S bond of $1.880(3)$ Á to the quarternary centre. The corresponding oxo compound does not undergo self coupling in triethyl phosphite, possibly due to a retro Diels Alder reaction taking place, as has been observed elsewhere. $^{44}$ 

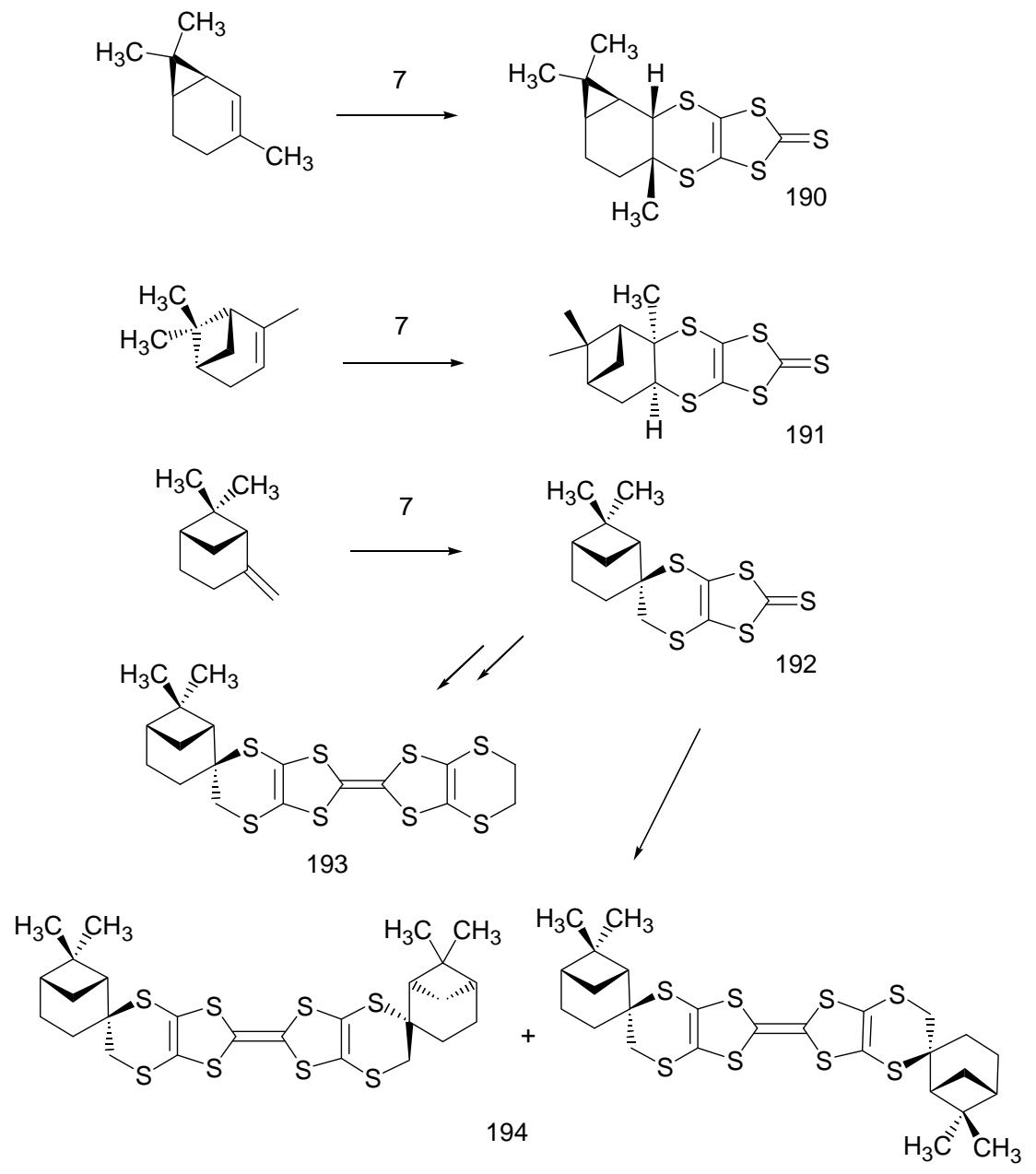

Scheme 22

Given the exceptional diastereoselectivity found in the latter reactions of trithione 7 the reaction was extended to the enantiopure alkene 195 derived from $D$-mannitol which gave two separable diastereomeric thiones 196 (31\%) and 197 (6\%) (Scheme 23). The major product 196 underwent S/O exchange, cross coupling with unsubstituted thione 9 in triethyl phosphite and final hydrolysis of the ketals to give the tetrol 198 which has four stereocentres, while homocoupling and hydrolysis gives the octol 199. ${ }^{24}$ There is thus considerable scope for using this methodology to prepare a range of chiral conducting materials. 

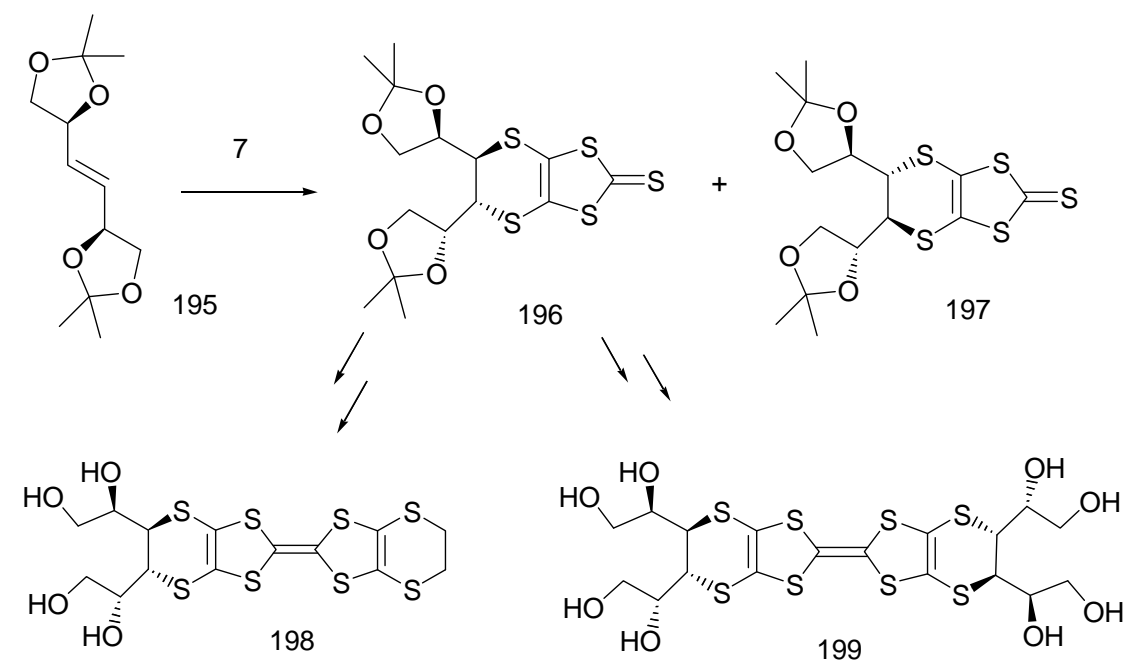

Scheme 23

\section{Unsaturated analogues of ET: VT.}

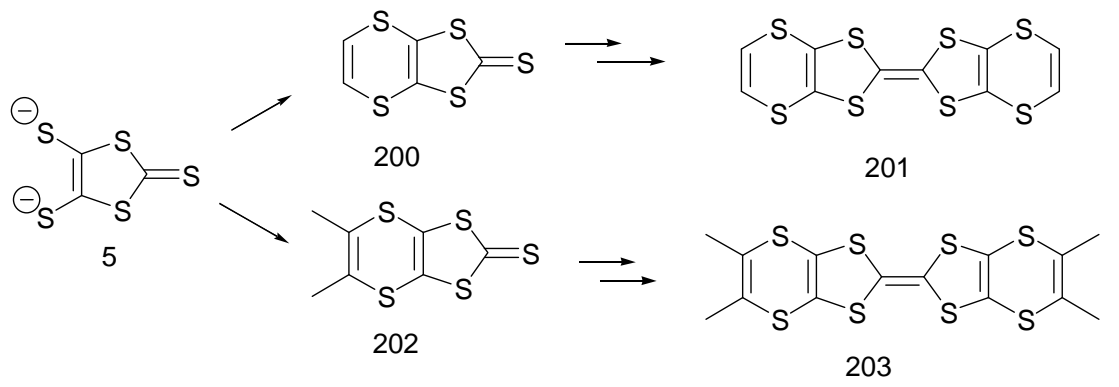

Scheme 24

Introduction of double bonds on the ethylene bridges gives bis(vinyldithio)TTF, 201, known as VT, and brings some simplifications and small changes compared to ET. The substituted donors are not chiral and so the number of stereoisomers available for a particular combination of substituents is reduced. There is one reversible oxidation potential, which is $c a 0.14 \mathrm{~V}$ higher than for ET. The conformations of the outer rings are characterized by a bend about the S---S vector of $c a 48^{\circ}$, in contrast the outer rings of ET systems which can vary between envelope, half chair, or even boat, depending on the substituents. Hence there has been significant progress in the synthesis of VT and its methyl derivatives (Scheme 24). Reaction of dithiolate 5 or its zinc complex with 1,2dibromoethene, ${ }^{98}$ or 1,2-dihalo-1-ethoxyethane followed by acid or base, ${ }^{46,99-101}$ gave the unsaturated thione 200, which was converted to VT 201 by standard methodology. Similar reactions with 3-halobutyne, ${ }^{46,99,101}$ or with 3-chlorobutan-2-one followed by treatment with acid, ${ }^{100}$ gave the dimethylated thione 202, which was converted to the tetramethyl-VT 203. The thione $\mathbf{2 0 0}$ has also been prepared by cycloaddition of trithione 7 with vinyl phenyl sulfoxide. ${ }^{102}$ Alternatively, reaction of the disodium salt of dithiolate 5 with gave thione 202. ${ }^{99}$ Ozturk discovered that treatment of bis(aroylmethylthio)1,3- 
dithiolethiones 204 with Lawesson's reagent or phosphorus pentasulfide gave the substituted thiones 207-209, ${ }^{104}$ possibly forming via a nine membered cyclotrithiatriene intermediate 206 (Scheme 25). Thiones were transformed by cross coupling to the monosubstituted donors 212-214, ${ }^{104}$ and to the enantiopure dihydroxy donor $215 .{ }^{105}$ Furthermore, the bis(acetylmethylthio) thione 205 is converted by the same procedure to thione 210 which could be converted to donor 211. ${ }^{104}$ Ozturk has extended this work to prepare the fully unsaturated donor tetraphenyl-VT 220. ${ }^{106}$ Treatment of the bis(desyl)thione 216 with phosphorus pentasulfide in toluene in the dark gave a $65 \%$ yield of the diphenyl thione 217, which could be converted by normal procedures to tetra-phenyl-VT 220. The conditions are critical, since use of Lawesson's reagent instead of phosphorus pentasulfide led only to the fused thiophene 218, and using phosphorus pentasulfide in light gave 218 and the dithiole 219.<smiles></smiles><smiles>[X]c1ccc(C2=CSc3sc(=S)sc3S2)cc1</smiles>
$207 \mathrm{X}=\mathrm{H}$ $208 X=\mathrm{Br}$ $205 \mathrm{R}=\mathrm{Me}$ $209 \mathrm{X}=\mathrm{OMe}$
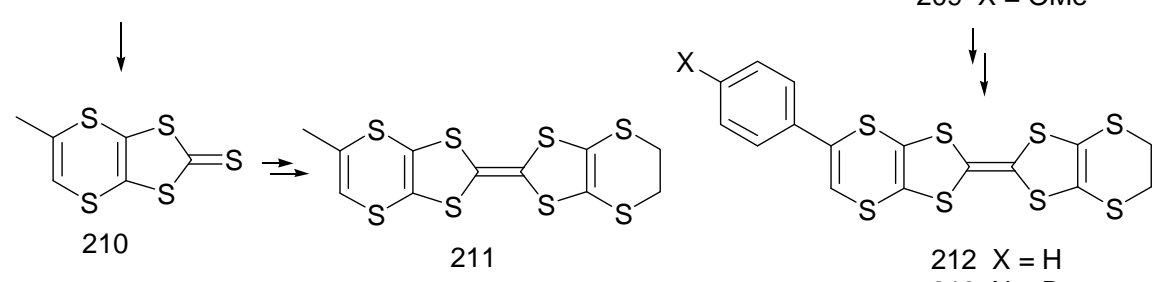

$212 \mathrm{X}=\mathrm{H}$

$213 X=\mathrm{Br}$ $214 \mathrm{X}=\mathrm{OMe}$

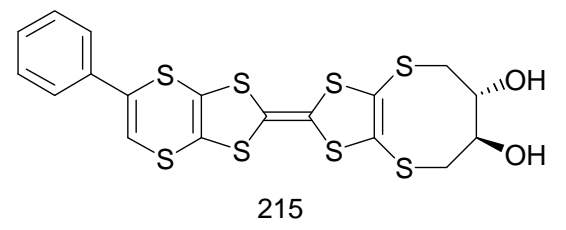

Scheme 25 

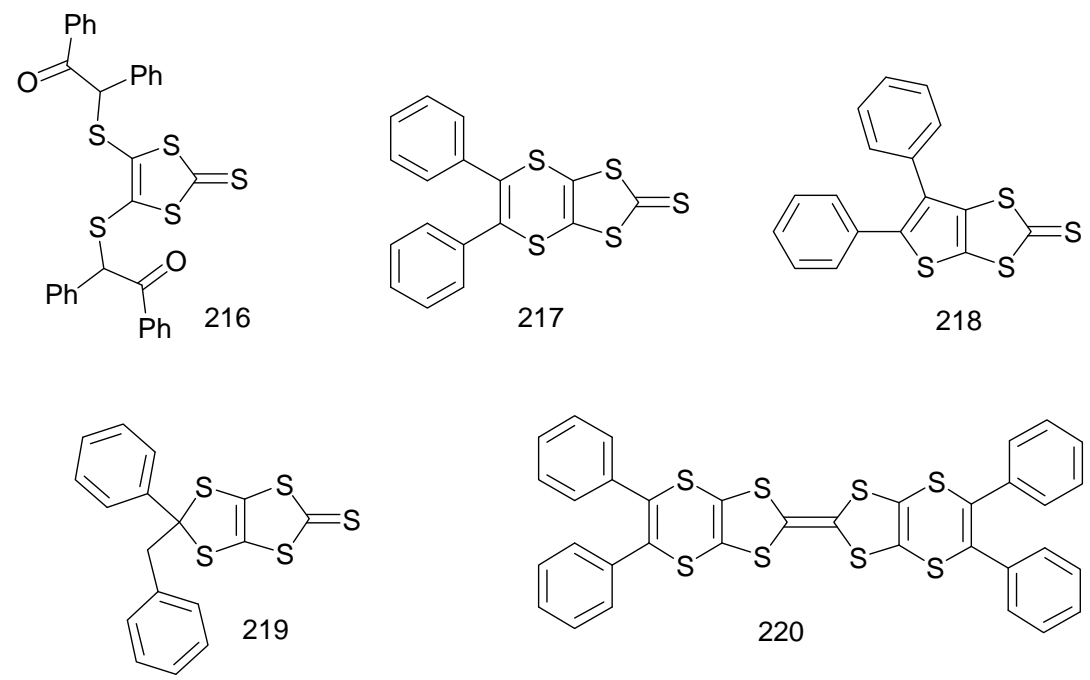

Cycloadditions of trithione 7 with electron deficient alkynes has also been used to yield unsaturated thiones 221-223 (Scheme 26), though the yield of 222 is low. ${ }^{107-109}$ Conversion of $\mathbf{2 2 1}$ to its bis(acetal), formation of the oxo compound and homocoupling in tri-isopropyl phosphite gave the tetraacetal substituted donor 225. ${ }^{107}$ Use of this more sterically hindered coupling agent improved the yield of the last step. Mono-acetal 222 has been converted to its oxo compound and cross coupled with unsubstituted thione $\mathbf{9}$, and finally hydrolysed to give the aldehyde substituted donor 226. ${ }^{108}$ The diester thione 223 could be homo coupled using triphenyl phosphine, but the donor product had lost one sulfur atom from one outer ring. The corresponding oxo compound on treatment with triethyl phosphite gave only the Arbusov product, tetra(methylthio)TTF. ${ }^{109}$ An alternative approach is to cyclise the trithione 7 with an alkene and dehydrogenate the product, e.g. with DDQ, for example in the preparation of the unsaturated ferrocenyl thione 228 from thione 227 which was converted in two steps into the homocoupled product 229 as a mixture of two diastereoisomers. ${ }^{110}$ Dithiolate 5 reacts with the cyclic sulfate ester of dimethyl tartrate to give a mixture of cis and trans isomers of the diester 145, which can also be dehydrogenated with DDQ to yield 223 . $^{76}$ 


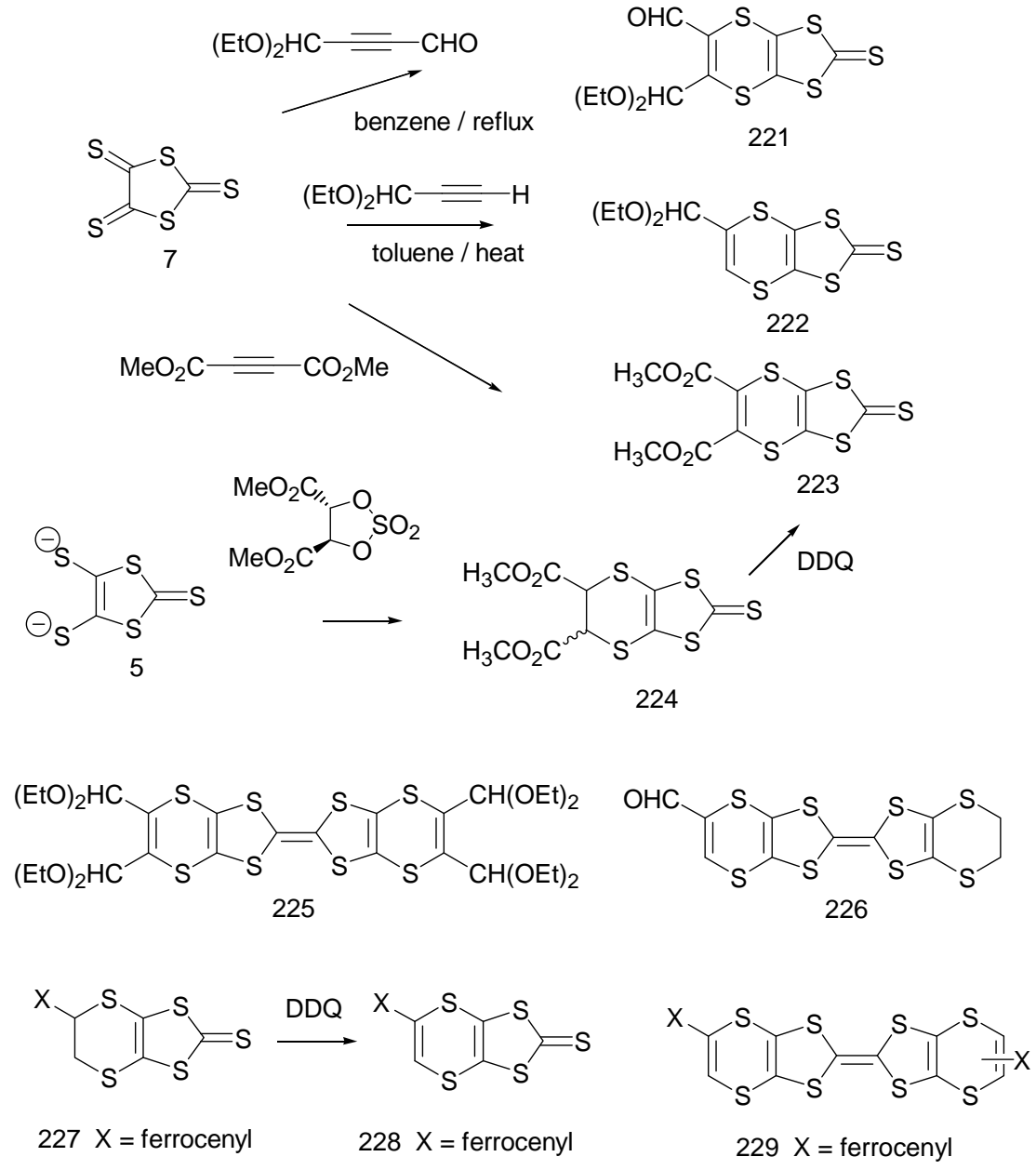

Scheme 26

Radical cation salts of VT and tetramethyl-VT with a range of linear, tetrahedral and octahedral anions and with bromide have been reported, as well as several charge transfer compounds with TCNQ and related compounds. ${ }^{98,111}$

\section{Future Developments.}

The preparation of hybrid materials combining two different properties which can interact is an important current theme in materials research, for example combining conducting and magnetic properties in (BETS) ${ }_{2} \mathrm{FeBr}_{4}{ }^{8}$ In the TTF field Fourmigué and Avarvari have prepared a radical cation salt of a molybdenum complex of TTF functionalised with phosphines, ${ }^{112}$ and complexes of further ligand-bearing TTFs have been reported. ${ }^{113}$ This contrasts with Day's use of anionic metal complexes as counterions in electrocrystallisations. ${ }^{114} \mathrm{Xu}$ 's pyridine substituted derivatives 79-80 were the first such materials in the ET field ${ }^{47}$ but a new series of materials bearing metal binding groups on sidearms has been reported built from hydroxyl or amino functionalized ETs. ${ }^{63}$ Mono- and bidentate $\mathrm{N}$-containing heterocycles have been introduced as their thiolates by substitution on the tosylate $\mathbf{2 3 0}$ to give the substituted thione which was converted to 
donors 231-233 by standard procedures (Scheme 27). Alternatively, the heterocyclic ligand can be introduced on a hydroxylated donor e.g. HEET 116, by ester formation to give 234 (as a meso and $d l$ pair) or 235, or by substitution on its tosylate, e.g. preparation of donor 236 (Scheme 28). Similarly, pyridine groups have been attached by amide links to ET systems as in compounds $\mathbf{1 3 5}$ and $\mathbf{1 6 2}$. Following this general idea, there is now considerable to introduce other properties into the ET system via the hydroxyl, amino or ester functionalized donors now available.

The availability of functionalized ETs opens up the possibilities for incorporation into dendrimeric or polymeric systems. Chinese workers have reported initial studies on preparing conducting copolymers prepared from adipoyl chloride and ET derivatives substituted at each end with a hydroxymethyl group, and also from ET diesters and hexane-1,6-diol. ${ }^{115}$ The wide range of precursor oxo compounds now available also opens up access to new metal dithiolene complexes since the dithiolates are accessible through base cleavage of the carbonyl group. Functionalised ETs are likely to find applications in areas of nanotechnology, for example, the preparation of conducting thin films by Langmuir -Blodgett methods, an area where Troitsky has been carrying out pioneering work using hexadecyl-ET 45. ${ }^{116}$ Particular achievements have included use of hexadecylTCNQ along with donor 45, use of combinations of charge transfer complex formation and chemical oxidation, and new deposition techniques, and synthetic approaches to new donors are now open. New techniques for deposition of donor monolayers have also been reported. ${ }^{117}$ British and Russian workers have also used octadecyl-ET 46 with 10-20\% stearic acid to form Langmuir-Blodgett layers of significant conductivities in both deposited and iodine doped states ( $\sigma=0.1$ and $1 \mathrm{~S} \mathrm{~cm}^{-1}$ respectively) which retain their conductivities for up to four weeks in air. ${ }^{26}$ Furthermore, donors with liquid crystalline properties have begun to appear, notably 237 and 238 from Bushby, which show calamitic and discotic phases respectively. ${ }^{118}$ New approaches to electrocrystallisation will also aid the preparation of radical cation salts. ${ }^{19}$ Indeed, it can be expected that the charge transfer interactions of the donors and the conductivities of their radical cation salts will find increasing applications now that the important functionalized building blocks are available, and they will play an important role in the development of new multi-functional materials. 


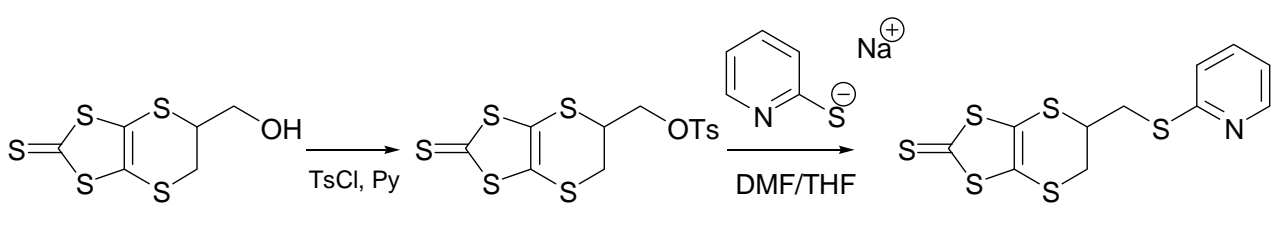

98

230
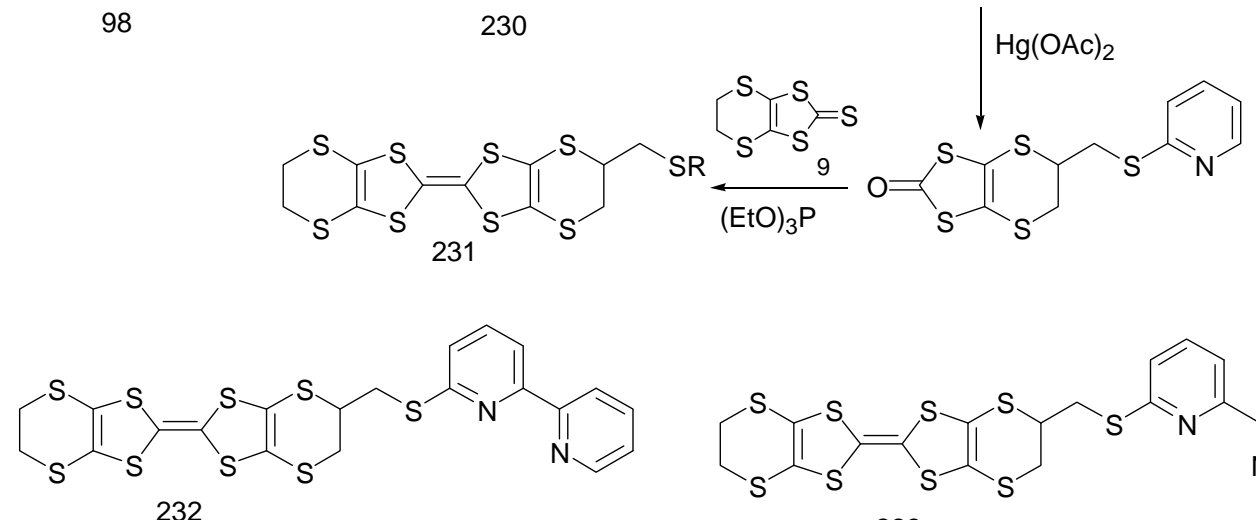

Scheme 27
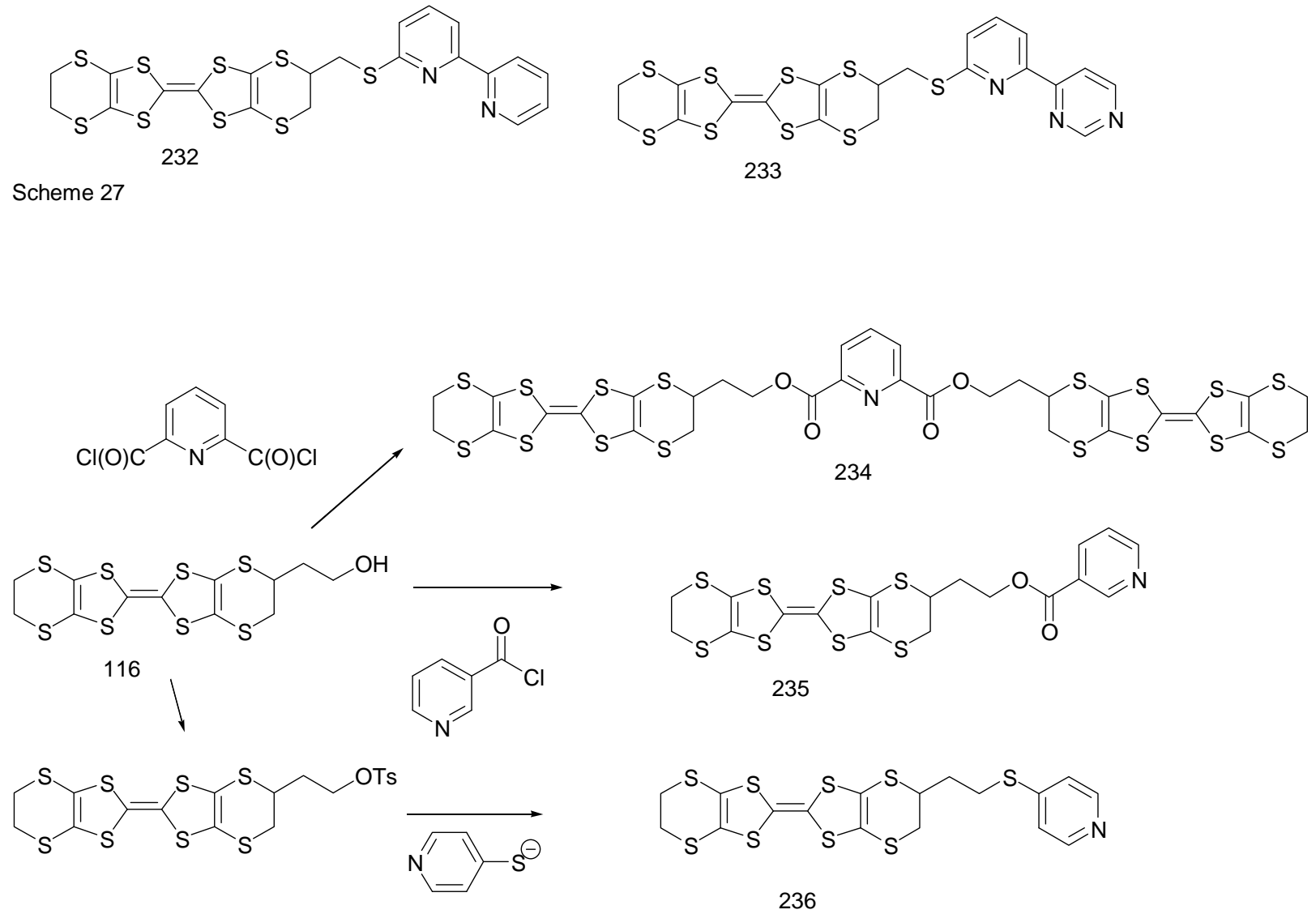

Scheme 28

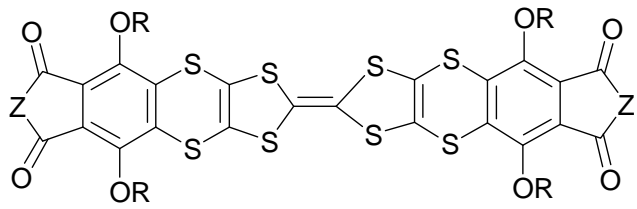

$237 \mathrm{Z}=\mathrm{O} ; \mathrm{R}=\left(\mathrm{CH}_{2}\right)_{2} \mathrm{CH}\left[\left(\mathrm{CH}_{2}\right)_{8} \mathrm{CH}_{3}\right]_{2}$

$238 \mathrm{Z}=\mathrm{NMe} ; \mathrm{R}=\left(\mathrm{CH}_{2}\right)_{2} \mathrm{CH}\left[\left(\mathrm{CH}_{2}\right)_{8} \mathrm{CH}_{3}\right]_{2}$ 


\section{Acknowledgements.}

We thank the Nottingham Trent University for support, Prof. P. Batail and the Laboratoire de Chimie Inorganique, Materiaux et Interfaces, CNRS, Université d'Angers, France, for a visiting professorship, and Prof. E.C. Constable and Prof. C. Housecroft for a sabbatical period in the Chemistry Department, University of Basel, Switzerland.

\section{References.}

1. J.-I.Yamada, "TTF Chemistry: Fundamentals and Applications of Tetrathiafulvalene", Springer-Verlag, Berlin and Heidelberg, 2004; J.L. Segura, N. Martin, Angew. Chem. Int. Ed., 2001, 40, 1372; M. R. Bryce, J. Mater. Chem., 2000, 10, 589; J.M. Williams, Acc. Chem. Res., 1985, 18, 261; F. Wudl, Acc. Chem. Res., 1984, 17, 227; M. B. Nielsen, C. Lomholt, J. Becher, Chem. Soc. Rev., 2000, 29, 153; J.M. Fabre, Chem. Rev., 2004, in press; M. Iyoda, M. Hasegawa, Y. Miyake, Chem. Rev., 2004, in press.

2. P. Day, Comp. Rend. Chem., 2003, 6, 301; J. Singleton, C. Mielke, Contemp. Phys. 2002, 43, 63 \& Physics World, 2002, 35.

3. H. Taniguchi, M. Miyashita, K. Uchiyama, K. Satoh, N. Mori, H. Okamoto, K. Miyagawa, K. Kanoda, M. Hedo, Y. Uwatoko, J. Phys. Soc. Jpn., 2003, 72, 468; T. Ishiguo, K. Yamaji, G. Saito, “Organic Superconductors”, Springer Verlag, Berlin, 1998; M.H. Whangbo, C.C. Torardi, Acc. Chem. Res., 1991, 24, 127; J.M. Williams, A.J. Schultz, U. Geiser, K.D. Carlson, A.M. Kini, H.M. Wang, W.K. Kwok, M.H. Whangbo, J.E. Shirber, Science, 1991, 252, 1501.

4. M. Kurmoo, A.W. Graham, P. Day, S.J. Coles, M.B. Hursthouse, J.L. Caulfield, J. Singleton, F.L. Pratt, W. Hayes, L. Ducassse, P. Guionneau, J. Amer. Chem. Soc., 1995, 117, 12209.

5. E. Coronado, J.R. Galen-Mascaros, C.J. Gomez-Garcia, V. Laukhin, Nature, 2000, $408,447$.

6. T. Imakubo, T. Shirahata, M. Kibune, Chem. Commun., 2004, in press; J. Hellberg, M. Moge, D. Bauer, J.-U. von Schutz, J. Chem. Soc. Chem. Commun., 1994, 817; J.S. Zambounis, C.W. Mayer, Tetrahedron Lett., 1991, 32, 2741; T. Mori, H. Inokuchi, A.M. Kini, J. M. Williams, Chem. Lett., 1990, 1279; T. Suzuki, H. Yamuchi, G. Srdanove, K. Hinkelmann, F. Wudl, J. Am. Chem. Soc., 1989, 111, 3108; R. Kato, H. Kobayashi, A. Kobayashi, Syn. Met., 1987, 19, 629.

7. P. Hudhomme, S. Le Moustarder, C. Durand, N. Gallego-Planas, N. Mercier, P. Blanchard, E. Levillain, M. Allain, A. Gorgues, A. Riou, Chem. Eur. J., 2001, 7, 5070 . 
8. H. Kobayashi, B. Zhang, H. Tanaka, T. Otsuka, E. Fujiwara, A. Kobayashi, Syn. Met., 2003, 137, 1157; B. Zhang, H. Tanaka, H. Fujiwara, H. Kobayashi, E. Fujimwara, A. Kobayashi, J. Amer. Chem. Soc., 2002, 124, 9982; S. Uji, H. Shinagawa, T. Tereshima, T. Yakabe, Y. Teral, M. Tokumoto, A. Kobayashi, H.Tanaka, H. Kobayashi, Nature, 2001, 410, 908.

9. V. Krstic, G.L.J.A. Rikken, Chem. Phys. Lett., 2002, 364, 51; G.L.J.A. Rikken, J. Folling, P. Wyder, Phys. Rev. Lett., 2001, 87, art. no. 236602.

10. T. Otsubo, K. Takimiya, Bull. Chem. Soc. Jpn., 2004, 77, 43; K. Takimiya, T. Jigami, M. Kawashima, M. Kodani, Y. Aso, T. Otsubo, J. Org. Chem., 2002, 67, 4218; M. Kodani, K. Takimiya, Y. Aso, T. Otsubo, T. Nakayashiki, Y. Misaki, Synthesis, 2001, 1614; A. Chesney, M.R. Bryce, S. Yoshida, I.F. Perepichka, Chem. Eur. J. , 2000, 6, 1153 .

11. J.S. Zambounis, C.W. Mayer, Tetrahedron Lett., 1991, 32, 2737; C.W. Mayer, J.S. Zambounis, Eur. Pat. Appl., 1991, 90-810497.

12. T. Konoike, K. Namba, T. Shinada, K. Sakaguchi, G.C. Papavassiliou, K. Murata, Y. Ohfune, Synlett, 2001, 1476.

13. T.K. Hansen, I. Hawkins, K.S. Varma, S. Edge, S. Larsen, J. Becher, A.E. Underhill, J. Chem. Soc. Perkin Trans 2, 1991, 1963; G. Le Costumer, Y. Mollier, J. Chem. Soc. Chem. Commun., 1980, 38.

14. N. Saygili, R. J. Brown, P. Day, R. Hoelzl, P. Kathirgamanathan, E.E.R. Mageean, T. Ozturk, M. Pilkington, M.M.B. Qayyum, S.S. Turner, L. Vorwerg, J.D. Wallis, Tetrahedron, 2001, 57, 5015.

15. J.D. Dunitz, A. Karrer, J.D. Wallis, Helv. Chim. Acta, 1986, 69, 69.

16. R. J. Brown, G. Cameresa, J.-P. Griffiths, P. Day, J. D. Wallis, Tetrahedron Lett., 2004, 45, 5103.

17. N. Hui, R.J. Brown, J.-P. Griffiths, P. Day, J. D. Wallis, manuscript in preparation.

18. O.Y. Neilands, Y.Y. Katsens, Y.N. Kreitsberga, Zh. Org. Khim., 1989, 25, 658.

19. N. Svenstrup, J. Becher, Synthesis, 1995, 215.

20. C. Wang, A.S. Batsanov, M.R. Bryce, J.A.K. Howard, Synthesis, 1998, 1615.

21. N. Svenstrup, K.M. Rasmussen,T.K. Hansen, J. Becher, Synthesis, 1994, 809. 
22. S. Kimura, H. Suzuki, T. Maejima, M. Suto, K. Yamashita, S. Ichikawa, H. Mori, H. Motiyama, T. Mochida, Y. Nishio, K. Kajita, J. Phys. IV France, 2004, 114, 521.

23. T. Ozturk, N. Saygili, S. Oskara, M. Pilkington, C.R. Rice, D. A. Tranter, F. Turksoy, J.D. Wallis, J. Chem. Soc. Perkin Trans. 1, 2001, 407.

24. R.J. Brown, N. Hui, P. Day, J.D. Wallis, manuscript in preparation.

25. B. Y. Khodorkovskii, G. Pukitis, A.Y. Puplovskii, A. Edzina, O.Y. Neilands, Khim. Get. Soed., 1990, 131.

26. L.M. Goldenberg, V.Y. Khodorkovsky, J.Y. Becker, P. J. Lukes, M.R. Bryce, M.C.Petty, J. Yarwood, Chem. Mater., 1994, 6, 1426.

27. G.C. Papavassiliou, G.A. Mousdis, S.Y. Yiannopoulos, V.C. Kakoussis, J.S. Zambounis, Syn. Met., 1988, 27, B373-B378.

28. E.V.K.S. Kumar, J.D. Singh, H.B. Singh, K. Das, J.V. Yakhmi, R.J. Butcher, J. Chem. Soc. Perkin Trans. 1, 1998, 1769; J.D. Singh, H.B. Singh, J. Chem. Soc. Perkin Trans. 1, 1992, 2913.

29. A. Karrer, J.D. Wallis, J.D. Dunitz, B. Hilti, C.W. Mayer, M. Bürkle, J. Pfeiffer, Helv. Chim. Acta, 1987, 70, 942; M. M. Freund, J.L. Olsen, J.D. Wallis, A. Karrer, J.D. Dunitz, B. Hilti, Jpn. J. App. Phys., Part 1, 1987, 26(Suppl. 26-3), 895.

30. J.D. Wallis, J.D. Dunitz, Acta Crystallogr. 1988, C44, 1037.

31. S. Matsumiya, A. Izuoka, T. Sugawara, T. Taruishi, Y. Kawada, Bull. Chem. Soc. Jpn., 1993, 66, 513.

32. B. Chen, F. Deilacher, M. Hoch, H.J. Keller, P. Wu, P. Armbruster, R. Geiger, S. Kahlich, D. Schweitzer, Syn. Met., 1991, 42, 2101.

33. J.S. Zambounis, C.W. Mayer, K. Hauenstein, B. Hilti, W. Hofherr, J. Pfeiffer, M. Buerkle, G. Rihs, Adv. Mater., 1992, 4, 33.

34. J.S. Zambounis, C.W. Mayer, K. Hauenstein, B. Hilti, W. Hofherr, J. Pfeiffer, M. Buerkle, G. Rihs, Mat. Res. Soc. Symp. Proc., 1992, 247, 509.

35. S. Matsumiya, A. Izuoka, T. Sugawara, T. Taruishi, Y. Kawada, M. Tokumoto, Madoka, Bull. Chem. Soc. Jpn., 1993, 66, 1949.

36. A.M. Kini, J.P. Parakka, U. Geiser, H.-H. Wang, F. Rivas, E. DiNino, S. Thomas, J.D. Dudek, J. M. Williams, J. Mater. Chem., 1999, 9, 883. 
37. R. Medne, J. Kacens, I. Kraupsa, O.Y. Neilands, Khim. Geter. Soed., 1991， 10, 1317.

38. J. Kreicberga, J. K. Balodis, I. Kraupsa, O. Neilands, Zh. Org. Khim., 1988, 24, 1243.

39. R.P. Shibaeva, L.P. Rozenberg, Kristallografiya, 1991, 36, 1158.

40. G.G. Abashev, E. V. Shklyaeva, V.S. Russkikh, S. Krol, Mend. Comm., 1997, 157.

41. G.G. Abashev, V.S. Russkikh, E.V. Shklyaeva, V.I. Vladykin, Zh. Org. Khim., 1995, 31, 1705.

42. K.S. Varma, J. Evans, S. Edge, A.E. Underhill, G. Bojesen, J. Becher, J. Chem. Soc. Chem. Commun., 1989, 257.

43. Q. Fang, M.-H. Jiang, Z. Qu, J.-H. Cai, H. Lei, W.-T. Yu, Z. Zhuo, J. Mater. Chem., 1994, 4, 1041; Q. Fang, W.-T. Yu, J.H. Xu, H. Lei, M.H. Jiang, Acta Crystallogr., 1994, C50, 1519; Q. Fang, J.-H. Xu, W.-T. Yu, S.-Y. Guo, D. Xu, M.H. Jiang, Ниахие Хиеbao, 1995, 53, 645.

44. D.-Y.Noh, H.-J. Lee, J. Hong, A.E. Underhill, Tetrahedron Lett., 1996, 37, 7603.

45. H.-J. Lee, D.-Y. Noh, Bull. Kor. Chem. Soc., 1998, 19, 340.

46. T. Nogami, K. Inoue, T. Nakamura, S. Iwasaka, H. Nakano, H. Mikawa, Syn. Met., 1987, 19, 539.

47. W. Xu, D. Zhang, H. Li, D. Zhu, J. Mater. Chem., 1999, 9, 1245.

48. L. M. Goldenberg, J.Y. Becker, O. P.-T. Levi, V.Y. Khodorkovsky, L.M. Shapiro, M.R. Bryce, J.P. Cresswell, M.C. Petty, J. Mater. Chem., 1997, 7, 901; H.J. Nam, H.J. Lee, D.-Y. Noh, Polyhedron, 2004, 23, 115.

49. H. Müller, A. Lerf, H.P. Fritz, K. Andres, Syn. Met., 1991, 42, 2381; H. Müller, H.P. Fritz, R. Nemetschek, R. Hackl, W. Biberacher, C.P. Heidemann, Zeit. Natur., B: Chem. Sci., 1992, 47, 718; H. Müller, S. Fiedler, M. Saad, C. Riekel, Syn. Met., 1997, 86, 1885.

50. J.P. Parakka, A.M. Kini, J.M.Williams, Tetrahedron Lett., 1996, 37, 8085; J.P. Parakka, A.M. Kini, J.M. Williams, Syn. Met., 1997, 86, 1805.

51. R.L.Meline, R.L. Elsenbaumer, J. Chem. Soc. Perkin Trans. 1, 1997, 3575.

52. W. Xu, D. Zhang, H. Li, L. Fan, D. Zhu, Synth. Comm., 2000, 30, 835. 
53. K.S. Varma, S. Edge, A.E. Underhill, J. Chem. Soc., Perkin Trans. 1, 1990, 2563; G.C. Papavassiliou, S.Y. Yiannopoulos, J.S. Zambounis, Chem. Scri., 1987, 27, 265.

54. M. Fourmigué, P. Batail, Chem. Rev., 2004, in press; T. Devic, M. Evain, Y. Moëlo, E. Canadell, P. Auban-Senzier, M. Fourmigué,P. Batail, J. Amer. Chem. Soc., 2003, 125, 3295; B. Domercq, T. Devic, M. Fourmigué, P. Auban-Senzier, E. Canadell, J. Mater. Chem., 2001, 11, 1570; M. Iyoda, E. Ogura, T.Tanako, K. Hara, Y. Kuwatani, T. Kato, N. Yoneyama, J. Nishijo, A, Miazaki, T. Enoki, Chem. Lett., 2000, 680.

55. O.J. Dautel, J. Larsen, M. Fourmigué, Chem. Commun., 2000, 1117.

56. O.J. Dautel, M. Fourmigué, J. Chem. Soc. Perkin Trans. 1, 2001, 3399.

57. M. Katsuhara, S. Kimura, T. Mori, Syn. Met., 2003, 135-136, 625.

58. E.V.K.S. Kumar, J.D. Singh, H.B. Singh, K. Das, B. Verghese, Tetrahedron, 1997, 53, 11627.

59. T. Ozturk, C.R. Rice, J.D. Wallis, J. Mater. Chem., 1995, 5, 1553.

60. H. Li, D. Zhang, B. Zhang, Y. Yao, W. Xu, D. Zhu, Z. Wang, J. Mater. Chem., 2000, 10, 2063.

61. W. Qin, B. Zhang, Y.X. Yao, Y.F. Li, D. Zhu, Chin. Chem. Lett., 1996, 7, 573; H.X. Li, D.Q. Zhang, W. Xu, D. Zhu, Chin. Chem. Lett., 2000, 11, 883.

62. F. Leurquin, T. Ozturk, M. Pilkington, J.D. Wallis, J. Chem. Soc. Perkin Trans. 1, 1997, 3173.

63. J.-P. Griffiths, R.J. Brown, B. Vital, P. Day, C.J. Matthews, J.D. Wallis, Tetrahedron Lett., 2003, 44, 3127.

64. W. Zhao, Y. Shen, Y. Li, J. Yang, Syn. Met., 1997, 89, 91; S.-G. Liu,Y.-Q. Liu, P.-J. Wu, Y.-F. Li, D. Zhu, Phos. Sulf. Silic. Rel. Elem., 1997, 127, 81.

65. H. Li, D. Zhang, W. Xu, L. Fan, D. Zhu, Syn. Met., 1999, 106, 111; K. Balodis, J. Kacens, J. Kraupsa, A. Edzina, O.Y. Neilands, Lat. Kim. Zur., 1991, 627.

66. A.I. Kotov, C. Faulmann, P. Cassoux, E.B. Yagubskii, J. Org. Chem., 1994, 59, 2626.

67. A.M. Kini, U. Geiser, H.-H. Wang, K.R. Lykke, J.N. Williams, C.F. Campana, J. Mater. Chem., 1995, 5, 1647.

68. J. Yamada, Y. Nishimoto, S. Tanaka, R. Nakanishi, K. Hagiya, H. Anzai, Tetrahedron Lett., 1995, 36, 9509; J. Yamada, S. Tanaka, J. Segawa, M. Hamasaki, 
K. Hagiya, H. Anzai, H. Nishikawa, I. Ikemoto, K. Kikuchi, J. Org. Chem., 1998, 63, 3952; J. Yamada, H. Akutsu, H. Nishikawa, K. Kikuchi, Chem. Rev., 2004, in press.

69. J. Yamada, S. Tanaka, H. Anzai, T. Sato, H. Nishikawa, I. Ikemoto, K. Kikuchi, J. Mater. Chem., 1997, 7, 1311.

70. A.I. Kotov, L.I. Buravov, V.V. Gritsenko, A.A. Bardin, S.V. Konvalikhin, O.A. Dyachecko, E.B. Yagubskii, K.V. Van, M. Mizuno, Syn. Met., 2001, 120, 861.

71. A.I. Kotov, L.I. Buravov, S.V. Konvalikhin, O.A. Dyachecko, E.B. Yagubskii, I. Malfant, T. Courcet, P. Cassoux, J. Akimoto, K. Honda, M. Mizuno, Syn. Met., 1999, $102,1630$.

72. J. Hellberg, K. Balodis, M. Moge, P. Korall, J.U. von Schuetz, J. Mater. Chem., 1997, 7,31 .

73. Y. Yamashita, M. Tomura, K. Imaeda, Mol. Crys. Liq. Crys. Sect. A, 2002, 380, 203.

74. J-P. Griffiths, A. A. Arnal, G. Appleby, J.D. Wallis, Tetrahedron Lett., 2004, 45, 2813.

75. W.-C. Wu, Y.-J. Shen, Youji Ниахие, 1999, 19, 587.

76. T. Ozturk, D.C. Povey, J.D. Wallis, Tetrahedron, 1994, 50, 11205.

77. M.R. Bryce, G.J. Marshallsay, Tetrahedron Lett., 1991, 32, 6033; G.J. Marshallsay, M.R. Bryce, G. Cooke, T. Joergensen, J. Becher, C.D. Reynolds, S. Wood, Tetrahedron, 1993, 49, 6849.

78. S. A. Baudron, N. Avarvari, P. Batail, C. Coulon, R. Clerac, E. Canadell, P. AubanSenzier, J. Amer. Chem. Soc., 2003, 125, 11583; K. Heuze, M. Fourmigué, P. Batail, J. Mater. Chem., 1999, 9, 2373; N. Mercier, M. Giffard, G. Pilet, M. Alain, P. Hudhomme, G. Mabon, E. Levillain, A. Gorgues, A. Riou, J. Chem. Soc. Chem. Commun., 2001, 2722; O. Neilands, V. Tilika, I. Sudmale, I. Grigorjeva, A. Edzina, E. Fonavs, I. Muzikante, Adv. Mater. Opt. Elec., 1997, 7, 93; A. Dolbecq, A. Guirauden, M. Fourmigue, K. Boubekeur, P. Batail, M.-M. Rohmer, M. Benard, C. Coulon, M. Sallé, P. Blanchard, J. Chem. Soc. Dalton Trans., 1999, 1241.

79. M. Mizuno, A.F. Garito, M.P. Cava, J. Chem. Soc. Chem. Commun., 1978, 18.

80. S. Kalyan, H.B. Singh, J.P. Jasinski, E.S. Paight, R. Butcher, J. Chem. Soc. Perkin Trans 1, 1991, 3341.

81. R.P.Shibaeva, V.E. Korotkov, L.P. Rozenberg, N.D. Kushch, E.E. Laukhina, G.G. Abashev, E.B. Yagubskii, L.I. Buravov, A.V. Zvarykina, A. G. Khomenko, Syn. Met., 1991, 42, 1963 ; R.P. Shibaeva, E. Yagubskii, Chem. Rev., 2004, in press. 
82. V. Khodorkovski, A. Edzifna, O. Neilands, J. Mol. Elect., 1989, 5, 33.

83. V.S. Russkikh, G.G. Abashev, E.V. Shklyaeva, Russ. J. Org. Chem., 1997, 33, 408.

84. I.V. Rozhdestvenskaya, G.G. Abashev, I.I. Bannova, V.S. Russkikh, E.V. Shklyaeva, Zhur. Struk. Khim., 1991, 32, 164.

85. V.E. Korotkov, R.P. Shibaeva, Kristallografiya, 1991, 36, 1139.

86. T. Jorgensen, J. Becher, J.-C. Chambron, J.-P. Sauvage, Tetrahedron Lett., 1994, 35, 4339.

87. M. Asakawa, P.R. Ashton, V. Balzani, S.E. Boyd, A. Credi, G. Mattersteig, S. Menzer, M. Montalti, F.M. Raymo, C. Ruffilli, J.F. Stoddart, M. Venturi, D.J. Williams, Eur. J. Org. Chem., 1999, 985.

88. O.J. Dautel, M. Fourmigué, J. Org. Chem., 2000, 65, 6479.

89. O.J. Dautel, M. Fourmigué, E. Canadell, Chem. Eur. J., 2001, 7, 2635.

90. M. Fourmigué, O.J. Dautel, T. Devic, B. Domercq, Syn. Met., 2003, 133-134, 317.

91. O.J. Dautel, M. Fourmigué, E. Faulques, CrystEngComm, 2002, 4, 249; O.J. Dautel, M. Fourmigué, Inorg. Chem., 2001, 40, 2083.

92. O.J. Dautel, M. Fourmigué, New J. Chem., 2001, 25, 834.

93. E. Ojima, H. Fujiwara, H. Kobayashi, Adv. Mater., 1999, 11, 758.

94. T. Ozturk, F. Turksoy, J.D. Wallis, T. Umit, PCT Int. Appl., 2001.

95. S.-X. Liu, A. Neels, H. Stoeckli-Evans, M. Pilkington, J.D. Wallis, S. Decurtins, Polyhedron, 2004, 23, 1185.

96. G.A. Horley, T. Ozturk, F. Turksoy, J.D. Wallis, J. Chem. Soc. Perkin Trans. 1, 1998, 3225.

97. H. Kisch, B. Eisen, R. Dinnebier, K. Shankland, W.I. David, F. Knoch, Chem. Eur. J., 2001, 7, 738.

98. K.S. Varma, A.E. Underhill, Physica B+C, 1986, 143, 321.

99. R.R. Schumaker, V.Y. Lee, E.M. Engler, J. de Phys. Coll., 1983, C3, 1139.

100. Y.N. Kreitsberga, R.S. Medne, A.S. Edzhinya, M.V. Petrova, O.Y. Neilands, 
Khim. Get. Soed., 1986, 1470.

101. T. Nakamura, S. Iwasaka, H. Nakano, K. Inoue, T. Nogami, H. Mikawa, Bull. Chem. Soc. Japan, 1987, 60, 365.

102. J. Garin, R. Andreu, J. Orduna, J. Royo, Syn. Met., 2001, 120, 749.

103. K. Inoue, Y. Tasaka, O. Yamazaki, T. Nogami, H. Mikawa, Chem. Lett., 1986, 781.

104. T. Ozturk, Tetrahedron Lett., 1996, 37, 2821; F. Turksoy, J.D. Wallis, U. Tunca, T. Ozturk, Tetrahedron, 2003, 59, 8107.

105. T. Ozturk, F. Turksoy, E. Ertas, Phos. Sulf. Silic. Rel. Elem., 1999, 153-154, 417.

106. E. Ertas, T. Ozturk, J. Chem. Soc. Chem. Commun., 2000, 2039; F.B. Kaynak, S. Ozbey, T. Ozturk, E. Ertas, Acta Crystallogr., 2001, C57, 926.

107. P. Leriche, A. Gorgues, M. Jubault, J. Becher, J. Orduna, J. Garin, Tetrahedron Lett., 1995, 36, 1275.

108. Y. Ishikawa, T. Miyamoto, A. Yoshida, Y. Kawada, J. Nakazaki, A. Izuoka, T. Sugawara, Tetrahedron Lett., 1999, 40, 8819.

109. X.Yang, T.B. Rauchfuss, S. Wilson, J. Chem. Soc. Chem. Commun., 1990, 34.

110. H.-J. Lee, D.-Y. Noh, A.E. Underhill, C.-S. Lee, J. Mater. Chem., 1999, 9, 2359.

111. E.B. Yagubskii, A.I. Kotov, R.P. Shibaeva, A.A. Ignat'ev, O. Y. Nielands, J. Kreicberga, Dokl. Akad. Nauk. SSSR, 1986, 289, 676; H. Kobayashi, A. Kobayashi, T. Nakamura, T. Nogami, Y.Shirota, Chem. Lett., 1987, 559; S. Iwasaki, T.Nogami, Y. Shirota, Syn. Met., 1988, 26, 177.

112. N. Avarvari, M Fourmigué, Chem. Commun., 2004, 1300.

113. S. Bourguessa, K. Herve, S. Golhen, L. Ouahab, J.-M. Fabre, New J. Chem., 2003, 27, 560; F. Iwahori, S. Golhen, L. Ouahab, R. Carlier, Inorg. Chem., 2001, 40, 6541; B.W. Smucker, K.R. Dunbar, J. Chem. Soc. Dalton Trans., 2000, 1309.

114. S.S. Turner, C. Michaut, S. Durot, P. Day, T. Gelbrich, M.B. Hursthouse, J. Chem.Soc. Dalton Trans, 2000, 905; F. Setifi, S. Golhen, L. Ouahab, S.S. Turner, P. Day, CrystEngComm, 2002, 1, 1.

115. W. Wu, Y. Shen, Huadong Ligong Daxue Xuebao, 2000, 26, 107; W. Zhao, Y. Shen, Y. Li, J. Yang, Chin. J. Poly. Chem., 1998, 16, 214. 
116. V.I. Troitsky, T.S. Berzina, E. Dalcanale, M.P. Fontana, Thin Sol. Films, 2002, 405, 276; V.I. Troitsky, T.S. Berzina, M.P. Fontana, Coll. and Surf. A, 2002, $198-$ 200, 689; T.S. Berzina, V.I. Troitsky, M.P. Fontana, Mat. Sci. Eng. C, 2001, C15, 315; T.S. Berzina, V.I. Troitsky, E. Stussi, M. Mule, D. De Rossi, Syn. Met., 1993, 60, 111; T.S. Berzina, S.A. Shikin, P.S. Sotnikov, V.I. Troitsky, V.Y. Khodorkovsky, O.Y. Neilands, G.Pukitis, Top. Mol. Org. Eng., 1991, 7, 99.

117. S. Molas, J. Caro, J. Santiso, A. Figueras, J. Fraxedas, C. Meziere, M. Fourmigué, P. Batail, J. Cryst. Grow., 2000, 218, 399.

118. R.A. Bissell, N. Boden, R.J. Bushby, C.W.G. Fishwick, E. Holland, B. Movaghar, G. Ungar, J. Chem. Soc. Chem. Commun., 1998, 113.

119. A. Deluzet, S. Perruchas, H. Bengel, P. Batail, S. Molas, J. Fraxedas, Adv. Func. Mat., 2002, 12, 123. 